\title{
Numerical investigation of oxy-natural-gas combustion in a semi-industrial furnace: validation of CFD sub-models
}

Chiara Galletti $^{*}$, Giovanni Coraggio ${ }^{2}$, Leonardo Tognotti ${ }^{1,2}$

${ }^{1}$ Dipartimento di Ingegneria Industriale e Civile, Università di Pisa, Pisa, Italy,

${ }^{2}$ International Flame Research Foundation, Italy

\footnotetext{
* Corresponding author. Address: Dipartimento di Ingegneria Industriale e Civile, Università di Pisa, Largo L.

Lazzarino 2, I-56126 Pisa, Italy. Phone: 0039 0502217897, Fax: 0039 0502217866, E-mail; c.galletti@diccism.unipi.it.

[Digitare il testo]
} 


\begin{abstract}
The modeling through Computational Fluid Dynamics of oxy-natural-gas combustion experimental tests in a 3 MW semi-industrial furnace equipped with a low NOx burner is discussed. Since the complex geometry of the burner and the size of the furnace, a modeling strategy has been adopted to diminish the computational time and thus to make the simulations affordable. The model aims at validating different sub-models (e.g. combustion/kinetics, radiation/spectral) for oxy-natural-gas fired conditions through the comparison of predictions and in-flame measurements of temperature and chemical species. It is found that fast chemistry approaches are unable to predict the temperature field. The spectral model was also found to play a fundamental role for the correct analysis of such scale devices. Uncertainties in experimental and modelling results are discussed and compared.
\end{abstract}

Keywords:

Oxy-fuel combustion; semi-industrial tests; spectral models; Computational Fluid Dynamics; Eddy Dissipation Concept 


\section{Introduction}

Nowadays large attention is paid to oxy-fuel combustion, motivated by the possibility of coupling such technology to $\mathrm{CO}_{2}$ capture and storage (CCS) techniques for reducing greenhouse gases emission. In oxy-fuel combustion, a mixture of oxygen and recycled flue gases is used instead of air for the fuel oxidation. Consequently, a gas consisting of $\mathrm{CO}_{2}$ and $\mathrm{H}_{2} \mathrm{O}$ is obtained, with a concentration of $\mathrm{CO}_{2}$ ready for sequestration. Flue gases are recycled in order to make up the volume of the missing $\mathrm{N}_{2}$ and ensure the thermal capacity needed for the subsequent heat transfer operation in the boiler. Comprehensive reviews on oxy-fuel combustion are provided by Wall et al. [1], Toftegaard et al. [2] and Chen et al. [3].

In recent years there has been a large increase of the use of simulation tools, such as those based on Computational Fluid Dynamic (CFD). These tools could provide a strong asset for the development of novel combustion technologies such as oxy-fuel combustion. In particular, CFD calculations may be applied directly to the industrial scale of interest, thus avoiding scaling-up the results from lab-scale experiments. This appears especially relevant for combustion processes, for which scale-up procedures are generally complicated by the strong interaction between turbulence, reaction kinetics, heat release and radiation. However the use of CFD for the investigation and design of combustion systems faces some problems related to lack of rigorous validation of CFD models. This issue is very important as CFD sub-models for turbulent combustion (combustion models, kinetic schemes, and spectral models) have been generally developed for air-combustion cases and need to be validated and eventually revised for novel applications. Indeed one of the main research topics in oxy-fuel combustion is the development of suited models for $\mathrm{CO}_{2}$-enriched atmosphere [1].

CFD simulations at the industrial scales are computational demanding so that simplified models have to be generally adopted for the chemistry and radiative properties treatment. 
Global oxidation mechanisms are likely to be used for the modelling of industrial oxy-fuel combustion furnaces, due to the high computational costs of such simulations. However, available global reaction mechanisms have been formulated for conventional air combustion. The substitution of $\mathrm{CO}_{2}$ to $\mathrm{N}_{2}$ in oxy-fuel combustion may change the relevance of different elementary reactions, thus leading to a modification of the global rates [4]. Andersen et al. [5] evaluated the performance the two-step mechanisms of Westbrook and Drier, WD [6], and the four-step mechanism of Jones and Lindstedt, JL [7], for predicting a plug flow reactor fed with propane in both air and oxy-conditions (characterized by $28 \% \mathrm{O}_{2}$ and $72 \% \mathrm{CO}_{2}$ ). The two global schemes are largely employed to model methane oxidation in conventional combustion systems. Andersen et al. compared the results from these models to those from a detailed kinetic mechanism, finding that the prediction of $\mathrm{CO}$ levels was strongly unsatisfactory, so they suggested a revision of both models. The modification was found to be effective especially for the WD model. Moreover the authors recommended the use of finite rate approaches to model the turbulence/chemistry interaction. As a matter of fact the "mixed-isburned" approach for the turbulence/chemistry interaction treatment and traditionally used for air combustion modelling, is not likely to be applicable in reaction systems where reverse reactions play an important role, as is the case under oxy-fuel conditions due to $\mathrm{CO}_{2}$ decomposition at high temperatures. Recently Frassoldati et al. [8] investigated the performance of the JL scheme for oxy-combustion of methane without flue gas recycle (thus using pure $\mathrm{O}_{2}$ as oxidizer) by performing calculations in laminar counter-flow diffusion flames. The authors concluded that the water vapor dissociation reactions should be included in the mechanism to address the high temperature conditions with pure $\mathrm{O}_{2}$.

In addition to combustion/chemistry models, research needs in oxy-fuel combustion regard also spectral models. The Weighted-Sum of Gray Gases (WSGG) model is often adopted to 
evaluate the spectral properties of the participating medium; however model coefficients such as those of the 1-clear/3-gray gases model by Smith et al. [9], the most employed in numerical investigations of furnaces, have been generally derived for conventional air combustion. In oxy-fuel combustion the large amount of $\mathrm{CO}_{2}$ and $\mathrm{H}_{2} \mathrm{O}$ enhances the radiative transfer: so there is concern about the spectral model behavior for such a case, as it lies out of the region for which the spectral model has been tuned [9-13]. As a matter Gupta et al. [10] showed how the WSGG model by [9] under-predicts strongly the absorption coefficient in oxy-fuel conditions for large beam lengths, thus this aspect should mostly affect the modeling of large scale furnaces. Those investigations were based on the comparison between the WSGG model prediction and those obtained with banded models.

Recently some attempts have been made to improve the WSGG model in case of oxy-fuel combustion. For instance [10] proposed to introduce an additional gray gas to the 1-clear/3gray gases model of [9] in order better consider $\mathrm{CO}_{2}$ rich atmosphere. Such a modification was performed by evaluating the radiated properties through a Wide Band Model. Lately Johansson et al. [13] analyzed the radiative conditions in boilers with large pressure pathlengths for different $\mathrm{H}_{2} \mathrm{O} / \mathrm{CO}_{2}$ ratios through a Statistical Narrow Band model. The authors proposed two revisions of the WSGG model based on 1-clear/3-gray and 1-clear/4-gray gases for water vapor to carbon dioxide partial pressures ratios of 0.125 and 1 , which were better able to fit radiation properties in oxy-fuel conditions. Similarly Yin et al. [15] provided new oxy-fuel WSGG coefficients for different $\mathrm{H}_{2} \mathrm{O}$ and $\mathrm{CO}_{2}$ partial pressures. Such a model was lately tested by Yin et al. [16] who found that the effect of the spectral model was negligible for a $0.8 \mathrm{MW}$ furnace under oxy-natural-gas conditions, whereas affected strongly the heat transfer on a 609 MW utility boiler. The authors also analyzed the effect of three different 
global kinetic models of the simulation of oxy-fuel experiments in the $0.8 \mathrm{MW}$ furnace, finding a strong impact of the chemistry on predictions.

Ströhle [14] carried out an analysis of the radiative properties in a gas turbine combustor, again showing that the WSGG model with coefficients by [9] was unable to predict spectral properties for high $\mathrm{CO}_{2}$ concentration. The author then analyzed the performance of different wide band correlated-k method (WBCK).

In the present work, CFD simulations of experiments conducted with a 3 MW low-NOx burner installed in the FoSper furnace, a replica (placed at the ENEL experimental facility of Livorno, Italy) of the IFRF furnace n.1, in oxy-fired conditions fed with NG [17] [18] (oxyNG) are performed. Even though coal is the main fuel considered for oxy-fuel units (and there are several modeling activities on coal combustion, e.g. [19], as also reviewed by [3]), there are applications for which gas-fired oxy-fuel conditions are considered as in gas turbine combustors. Moreover the gaseous combustion modeling can help shedding light into gas radiation under oxy-fuel conditions in general.

Often CFD sub-models are tested on lab-scale devices, numerically and/or experimentally; however FoSper can provide datasets for validating them directly at the large scales were different effect may arise. For instance to our knowledge the data used by [16] are so far the only large-scale data used to understand the effect of a spectral model in real furnaces. As a matter of fact, FoSper has represented a reference case for a number of modelling activities with commercial and in-house codes during the last decades (e.g. [20]). However, no formalized procedures have been provided in such studies, for the assessment of the level of agreement between experiments and simulations. 


\section{Validation and uncertainties quantification approach}

The approach followed is fully described in recent IFRF Report [21]. The concept is based on the proper Design of Experiment (DoE) that is necessary for developing a joint experimental and modeling activity. In other words, in planning semi-industrial scale campaigns, one should try to answer the questions of what data and information is needed for modeling, and what is needed for validation before to design the experimental matrix. Within the validation activity, it is important to assess the level of agreement between the experimental data and computational results with quantifiable metrics and taking into account uncertainties in the experiment and in the model.

The validation activity can be performed at different levels of complexity that can be derived from the complete system through the construction of hierarchies which decompose the system of interest into levels of decreasing complexity [22]. The construction of hierarchies can also help in designing validation experiments. The errors associated to experiments (intrinsic, statistical errors, measuring position) have been discussed in [21]. The modelling approach should take into account the existence of "scenario" uncertainties (heat fluxes/temperature at the furnace wall), the complexity of the burner that needs grid reduction strategies (numerical solution error), the proper choice of kinetic and radiation submodels (modeling uncertainties), and finally some criteria of comparing experimental results and model predictions (validation metrics: quantitative evaluation of agreement between experiments and model predictions).

In the following sections the application of the validation approach is described for the present oxy-NG investigation. 


\section{Experimental campaigns}

The FoSper furnace is described in details in [17]. It has an internal square cross-section of 2 $\mathrm{m} \times 2 \mathrm{~m}$, is approximately $6.25 \mathrm{~m}$ long and is made of 11 independently water-cooled refractory-lined sections Figure 1a). Seven cooling loops are used to extract sufficient energy from the combustion chamber to maintain a temperature history comparable to a radiant section of a full-scale boiler operating with air. The cooling water flow rate and temperature for each section and loop are continuously monitored in order to determine the total heat extraction from the furnace.

The TEA-C (Figure 1b) is a Low NOx burner developed by Enel and Ansaldo used in industrial utility boilers; to allow the testing on the FoSper furnace, a scaled-down prototype of $3 \mathrm{MW}$ thermal power was used. In this prototype the oxidizer feeding is done by a wind-box with a vertical entrance, the oxidizer goes into the burner through two separate ducts secondary and tertiary - both having an axial movable swirler and a damper that controls the flow rate distribution. Two different sets of inclined palettes produce the swirling of the oxidizer with two different angles: the secondary duct palettes are inclined by $45^{\circ}$ and the tertiary duct palettes are inclined by $30^{\circ}$. These sets of palettes are independently movable along the axis of the burner and their position determines the intensity of the swirling, i.e. the swirl is higher when the palettes are close to the exit of the burner (Figure 1b). For the oxyNG tests considered herein, oxygen is fed, after mixing with RFG, through the secondary and tertiary duct. The primary duct, positioned on burner axis, provides the oxidizer/coal mixture to the combustion chamber with pulverized coal experiments (not considered in the present study). It is equipped by an internal axial swirler and a nozzle which makes a separation between coal rich and lean jets in order to enhance the in-flame NOx reduction effect. The primary oxidizer flow is maintained active even with NG experiments. 
For the NG firing operation, 8 lances inject the fuel through nozzles having two holes with an axis which forms a 45 degrees angle with the burner axis.

The experimental campaigns considered in the present paper regard NG combustion in oxyfired conditions using a recycle ratio of $\mathrm{R}=0.69$ [17]. The retrofitting of the furnace for oxyfired conditions is described in details in [18] even though a brief description is provided here. Flue gases coming from the furnace are sucked by a fan for flue gas extraction set upstream the bag filters. This fan is used also to control the pressure inside the combustion chamber. The flue gases go in the first convective section (flue/water heat exchanger) where they are cooled down to about $673 \mathrm{~K}$, and then cross the Ljungström exchanger that further reduce their temperature down to about $423 \mathrm{~K}$, by giving heat to the comburent. Then, cool flue gases are treated with two bag filters, and afterwards they are divided in two streams, one is sent to the stack and the other is recycled. A sketch of the plant is shown in Figure 2 where solid lines refer to standard air operation; dashed lines refer to the RFG and dashed-dotted lines to oxygen.

Table 1 reports the experimental conditions used for the present investigation. Details about different runs (i.e. air tests and oxy-NG combustion tests with a different recycled flue gas ratio) can be found in [17].

In oxy-NG combustion conditions, the furnace is kept in over pressure condition in order to limit the air in-leakage in the combustion chamber. The same setting of the furnace used in oxy combustion conditions has been kept also in the conventional combustion trials in order to perform a better comparison of the results.

The standard suction pyrometer is used to measure temperature and concentration of $\mathrm{CO}, \mathrm{CO}_{2}$, $\mathrm{NO}, \mathrm{O}_{2}$ inside the furnace. The instrument is inserted into the furnace through specifically 
designed 14 insertion windows (which provide the necessary seal and prevent the risk of flame escape out of the ports) in order to get the in-flame profiles of temperature and main gas species. In the standard suction pyrometer a platinum-rhodium thermocouple, protected from chemical attack by a sintered alumina sheath, is surrounded by two concentric radiation shields. The gases are drawn between the shields and over the sheath with high velocity so that the equilibrium thermocouple temperature is nearly that of gases without the need for correction. The gases sampled in the flame are drawn into a bubbler to separate the solid particles, go to a hot filter and then to the analyzing system. The concentrations of the $\mathrm{CO}$, $\mathrm{CO}_{2}, \mathrm{NO}$, are measured with infrared analysis and the $\mathrm{O}_{2}$ concentration with paramagnetic analyser.

A global estimation of the experimental uncertainties associated to the temperature and gas concentration measurements, has been recently performed [21] and they result to be always less than 5\%. Regarding the accuracy in the determination of the probe position, the error with respect to the furnace axes can be up to $1-2 \mathrm{~cm}$. Moreover it should be remarked that the measurements obtained with the suction pyrometer are an average of the value of the temperature (or gas composition) over a gas region of approximately $3 \mathrm{~cm}$ size inside the furnace.

Temperature at the furnace walls were also measured through thermocouples inserted by of a few $\mathrm{mm}$ inside the refractory material.

\section{Numerical model}

\subsection{Computational grid and domain}

The numerical model was developed with the fluid dynamics package Fluent by Ansys Inc. Due to the burner/furnace symmetries, just one quarter of the furnace was modeled in order to 
decrease the CPU time of the simulations. Fluid domains were used for the burner and the furnace, whereas the cooling loops were modeled as solid domains. This was made in order to facilitate the setting of heat extraction boundary condition from the cooling loops.

Due to the complexity of the burner much effort was devoted to the optimization of the grid. In particularly, two domains were chosen:

- a complete domain, in which the burner was represented in all details;

- a reduced domain in which the burner was "cut" by representing just a portion of the secondary and tertiary ducts.

The surfaces used to cut the complete domain are shown in Figure 3 and corresponds to the secondary (blue color) and tertiary (red color) duct inlet surfaces for the reduced domain.

The idea is to perform preliminary runs on the complex domain in isothermal conditions and thus to use obtained profiles of velocity, turbulence characteristics, temperature, species mass fractions to set proper boundary conditions at the secondary and tertiary duct inlets of the reduced domain. It is worth noting that such profiles must be derived from non-reactive complete domain simulations, as there are no available measurements. This procedure is somewhat different from that reported by Peters and Weber [26] for the modeling of flames in the IFRF furnace no.1. In that work, the aforementioned authors could employ the laser Doppler velocimetry (LDV) technique to get profiles of velocity and turbulent characteristics at the air inlet duct to be used for the furnace modeling. Moreover the geometry of the aerodynamically air staged burner used in their investigations allowed the adoption of a $2 \mathrm{D}$ (axisymmetric swirled) domain, so that LDV data could be taken just along a calibration line. In the present work, there is no optical access to the interiors of the TEA-C burner, so that the use of LDV technique is prevented. Moreover the strong 3D flow generated by the TEA-C 
burner would require a characterization of the velocity and turbulence field across measurement surfaces rather than along lines.

Grid independency studies were applied to both domains. Both grids were made of tetrahedrons and hexahedrons in the burner and its quarl, whereas a structured grid was used for the furnace. In order to make it possible, cooling loops were assumed to have a square cross section of perimeter equal to that of their real cross section circumference. Special refinements near the burner were also adopted. The complex domain leaded to a grid consisting of $4.5 \mathrm{M}$ cell (Figure $4 \mathrm{a}$ ), whereas the reduced domain leaded to $3.4 \mathrm{M}$ cells (Figure 4b). As a matter of fact, such $30 \%$ reduction in computational cells allows a considerable time savings because of the large computational cost of the simulations.

\subsection{Validation procedure and choice of boundary conditions}

In the framework of oxy-NG combustion experiments in the FoSper furnace, important validation aspects regard:

- the geometry, due to the complexity of the burner;

- the choice of the turbulence model, due to the presence of swirled flows;

- the choice of the combustion model/kinetic mechanisms;

- the choice of radiation/spectral models.

Moreover some boundary conditions (BCs) have to be properly set as not directly available from the experimental campaign. This is the case of air leakage, which unavoidably occurs when retrofitting existing air-fired furnaces to oxy-fired conditions. The amount of air leakage is reconstructed by performing a mass balance on the system based on the flue gas composition; however uncertainties still exist on the location of the air leakage. In the present work the air leakage was evaluated to be $194 \mathrm{~kg} / \mathrm{hr}$ by performing mass balances and trying to 
minimize the errors on both $\mathrm{CO}_{2}$ and $\mathrm{O}_{2}$ measurements; however one can chose to minimize the error on just one species. Air leakage occurs not in the furnace but also in the circuit. The distribution of air leakage from the furnace walls is hard to evaluate. Moreover, as mentioned previously, the furnace is kept at slight over-pressure in order to reduce air leakage; for this reason it is assumed that air leakage occurs mainly in the gas circuit. Therefore, in the present simulations air leakage is considered by adding air to the primary and secondary recycled flue gases streams, and distributing it proportionally to the two stream mass flow rates. Logically this procedure has to be validated.

For the BCs at the furnace walls, two options were investigated: a wall temperature profile (and emissivity) from measurements and a heat flux obtained from an energy balance on the overall furnace. The latter was found to be unable of correctly estimating the temperature field. In particular, an over-prediction of temperature in the bulk of the furnace by more than $300 \mathrm{~K}$ was observed at the first measuring port $(\mathrm{z}=0.17 \mathrm{~m})$, indicating that the hypothesis of a uniform heat flux leads to wrong BCs at the refractory walls. The knowledge of a temperature profile along the furnace walls leads to a strong improvement of predictions. Therefore wall temperature measurements are very attractive for providing boundary conditions to the numerical model.

According to the above points, a modeling program was defined and this is illustrated in the scheme of Figure 5. This consisted mainly of 4 steps:

1) In the first step, isothermal tests in air (with velocity measurements) were performed and results compares to predictions obtained with different turbulence models. The standard k- $\varepsilon$ turbulence model was compared to the SST k- $\omega$ model and to the Reynolds Stress models, which are more suited for the swirled flow under investigations. The simulation of such tests was performed with the complete domain. 
2) In the second step, BCs from gaseous combustion experiments (mass flow rates, species concentrations and temperatures) were used to set non-reactive simulations with the complete geometry.

3) In the third step, the same simulations of step 2 were performed on the reduced geometry. To do that, velocity, turbulence characteristics, temperature and species mass fractions profiles were extracted from the simulations of step 2 and set as BCs to the inlets of the secondary and tertiary ducts. If such approach is correct, velocity profiles inside the furnace obtained with simulations of steps 2 and 3 should coincide.

4) In the fourth step, gas combustion tests are simulated with the reduced domain. Inlet BCs are obtained from previous step. Simulated results are compared with available measurements of temperature and species concentrations inside the furnace.

The level of agreement between experiments and predictions is evaluated through the use of error validation metrics [27]. It is possible to define an average relative error, normalizing the absolute error by the estimated sample mean and summing over the range of the input variable:

$\left|\frac{\tilde{E}}{\bar{y}_{e}}\right|_{\text {avg }}=\frac{1}{N} \sum_{i=1}^{N}\left|\frac{y_{m, i}-\bar{y}_{e, i}}{\bar{y}_{e, i}}\right|$

where $\mathrm{N}$ is the number of observed points, $\mathrm{y}_{\mathrm{m}, \mathrm{i}}$ and $\mathrm{y}_{\mathrm{e}, \mathrm{i}}$ are the mean measurement and the predicted value of variable $y$ at the point $\mathrm{i}$. The relative error is used for temperature. For species concentrations it will be referred to average absolute errors, defined as $|\widetilde{E}|_{\text {avg }}=\frac{1}{N} \sum_{i=1}^{N}\left|y_{m, i}-\bar{y}_{e, i}\right|$

because chemical species concentrations may tend to zero value in some positions, thus leading to numerical divergence. 


\subsection{Physical model}

The reactive simulations were carried out by resolving Favre-averaged Navier-Stokes equations by means of a stationary pressure-based solver with double precision.

A property $\varphi$ can be decomposed into $\tilde{\varphi}$, which represents the Favre-average, and $\varphi^{\prime \prime}$, according to:

$\tilde{\varphi}=\frac{\overline{\rho \varphi}}{\bar{\rho}}$

$\varphi=\tilde{\varphi}+\varphi^{\prime \prime}$

The application of such average to the Navier-Stokes, species and enthalpy transport equations leads to:

$\nabla(\bar{\rho} \widetilde{\boldsymbol{u}})=0$

$\nabla(\bar{\rho} \widetilde{\boldsymbol{u}} \widetilde{\boldsymbol{u}})=-\nabla \bar{p}-\nabla\left(\bar{\rho} \widetilde{\boldsymbol{u}^{\prime \prime} \boldsymbol{u}^{\prime \prime}}\right)+\nabla \overline{\boldsymbol{\tau}}$

$\nabla\left(\bar{\rho} \widetilde{Y_{k}} \widetilde{\boldsymbol{u}}\right)=-\nabla \overline{\boldsymbol{J}_{\boldsymbol{k}}}-\nabla\left(\bar{\rho} \overline{Y_{k}^{\prime \prime} \boldsymbol{u}^{\prime \prime}}\right)+\overline{\dot{w}_{\boldsymbol{k}}}$

$\nabla(\bar{\rho} \tilde{\mathrm{h}} \widetilde{\boldsymbol{u}})=-\nabla\left(\overline{\boldsymbol{J}_{\boldsymbol{h}}}+\widetilde{\boldsymbol{u \tau}}\right)-\nabla\left(\bar{\rho} \widetilde{\mathrm{h}^{\prime \prime} \boldsymbol{u}^{\prime \prime}}\right)+\widetilde{\boldsymbol{u F}}+\overline{Q_{\text {rad }}}$

Hence, in the Equations (3)-(8) $\widetilde{\boldsymbol{u}}, \widetilde{Y_{k}}$ and $\tilde{\mathrm{h}}$ represent the Favre-averaged velocity, mass fraction of the $k$-th species and enthalpy, respectively. $\bar{\rho}, \bar{p}, \overline{\boldsymbol{J}_{\boldsymbol{k}}}, \overline{\boldsymbol{J}_{\boldsymbol{h}}}, \overline{Q_{\text {rad }}}$ and $\overline{\boldsymbol{\tau}}$ are the standard time-averaged density, static pressure, species and heat diffusive fluxes, radiant heat and stress tensor. The latter is expressed in terms of velocity field and viscosity through the costituitive equation.

The Reynolds stress tensor $-\bar{\rho} \widetilde{\boldsymbol{u}^{\prime \prime} \boldsymbol{u}^{\prime \prime}}$ should be expressend through the turbulence model. In the present case, reactive simulations were performed with the shear stress transport (SST) k- $\omega$ model of [24]. Such a model is based on the k- $\omega$ model formulation in the near wall region 
and switches to the standard k- $\varepsilon$ model in far field using suited blending function. The model is expected to be more accurate than the standard $\mathrm{k}-\varepsilon$ model in presence of swirling flows.

Recently Chen and Ghoniem [25] showed that the SST model k- $\omega$ could capture the flow structure in a swirl oxy-coal burner better than the RNG and standard k- $\varepsilon$ model.

Actually, the performance of different turbulence models in predicting the flow field in FoSper furnace equipped with TEA-C burner has been previously compared for isothermal tests [21], however differences should be expected in the performance of turbulence models between non- and reactive conditions [17] [28], so that results are of little significance.

Two different turbulence/chemistry interaction models were compared: the Eddy Dissipation Model (EDM) by Magnussen and Hjertager [29] and the Eddy Dissipation Concept (EDC) by Magnussen [30]. In the EDM model the chemical reactions are governed by turbulent mixing so that reaction rates are expressed as a function of the turbulent characteristics, basically the turbulent kinetic energy and its dissipation. This model is largely used for simulating combustion furnaces, however it does not account for finite rate chemistry effects, it being based on a mixed is burnt approach. According to EDC, combustion occurs in regions ("fine structures") of the flow where the dissipation of turbulent kinetic energy takes place; such regions are treated as perfectly stirred reactors (PSR). The mass fraction of the fine structures, $\gamma_{\lambda}$, and the mean residence time of the fluid within the fine structures, $\tau^{*}$, are provided by an energy cascade model, which describes the energy dissipation process as a function of the characteristic scales. Thus such a model is able to account for chemistry effect. To reduce the computational time, the in-situ adaptive tabulation (ISAT) method of Pope [31] with various error tolerances (decreased gradually) was employed when using EDC. Results were found to be independent on the ISAT error tolerance when this was lower than $10^{-5}$. 
The NG fuel was modeled as a mixture of $\mathrm{CH}_{4}(85.7 \%$ by vol $), \mathrm{C}_{2} \mathrm{H}_{6}(5.4 \%$ by vol $), \mathrm{C}_{3} \mathrm{H}_{8}(2.2$ $\%$ by vol), $\mathrm{N}_{2}(5.5 \%$ by vol $), \mathrm{CO}_{2}(1.2 \%$ by vol).

Different global kinetic mechanisms were tested for the fuel oxidation. The global kinetic mechanism of Westbrook and Drier [6] consisting of fuel oxidation $\left(\mathrm{CH}_{4}, \mathrm{C}_{2} \mathrm{H}_{6}, \mathrm{C}_{3} \mathrm{H}_{8}\right)$ to $\mathrm{CO}$ and subsequently oxidation of $\mathrm{CO}$ to $\mathrm{CO}_{2}$ is employed and will be denoted as WDair.

$\mathrm{CH}_{4}+1.5 \mathrm{O}_{2}=>\mathrm{CO}+2 \mathrm{H}_{2} \mathrm{O}$

$\mathrm{CO}+0.5 \mathrm{O}_{2}=>\mathrm{CO}_{2}$

$\mathrm{CO}_{2}=>\mathrm{CO}+0.5 \mathrm{O}_{2}$

Andersen et al. [5] proposed a modification of the rates of the $\mathrm{CO} / \mathrm{CO}_{2}$ subset (second and third reactions) to better predict oxy-fuel combustion; such a version is also tested and will be denoted as WDoxy.

The 4-step global kinetic mechanism by Jones and Lindstedt [7], namely JLair, was also employed for the $\mathrm{CH}_{4}$ oxidation subset, as it is extensively used for the modeling of industrial combustion devices.

$\mathrm{CH}_{4}+0.5 \mathrm{O}_{2}=>\mathrm{CO}+2 \mathrm{H}_{2}$

$\mathrm{CH}_{4}+\mathrm{H}_{2} \mathrm{O}=>\mathrm{CO}+3 \mathrm{H}_{2}$

$\mathrm{H}_{2}+0.5 \mathrm{O}_{2}<=>\mathrm{H}_{2} \mathrm{O}$

$\mathrm{H}_{2} \mathrm{O}+\mathrm{CO}<=>\mathrm{CO}_{2}+\mathrm{H}_{2}$

The mechanism consists of two irreversible reactions describing the initial oxidation steps of a hydrocarbon through addition with $\mathrm{O}_{2}$ and $\mathrm{H}_{2} \mathrm{O}$, respectively, and formation of $\mathrm{CO}$ and $\mathrm{H}_{2}$. The third and fourth reversible reactions control the rate of reaction for $\mathrm{CO}$ and $\mathrm{H}_{2}$. The revised version of the model proposed by [5], consisting of a modification of the third reaction rates, is also used, as will be denoted as JLoxy.

All kinetic schemes are summarized in Table 2. 
The $\mathrm{P} 1$ radiation model was employed although some simulations were performed also with the Discrete Ordinate model. The gas phase spectral properties were evaluated through the WSGG model, which computes the gas emissivity as:

$\varepsilon=\sum_{i} a_{i}(T)\left[1-\exp \left(-\kappa_{i}\left(p_{H 2 O}+p_{C O 2}\right) s\right)\right]$

where $s$ is the radiation beam length, $p_{\mathrm{H} 2 \mathrm{O}}$ and $p_{\mathrm{CO} 2}$ are the partial pressures of the absorbing gases $\mathrm{H}_{2} \mathrm{O}$ and $\mathrm{CO}_{2}$. The weight $a_{j}$ represents the fraction of the blackbody radiation that belongs to the spectral regions where the absorption coefficient is $\kappa_{i}$. The weights depend on temperature according to:

$a_{i}(T)=\sum_{j} b_{i, j}\left(T / T_{r e f}\right)^{j-1}$

Two different WSGG models were applied:

- the WSGG model available in the code which is a 1-clear/3-gray gas model with coefficients from [32];

- a revised version proposed by Johansson et al. [13] for oxy-fuel conditions, which is a 1-clear/4-gray gas model optimized for $\mathrm{H}_{2} \mathrm{O}$ to $\mathrm{CO}_{2}$ partial pressure ratio of 0.125 , which better approximates the dry flue gas recirculation of the present oxy-NG campaigns.

The latter model was applied by defining an ad hoc subroutine written in C++ language and its coefficients are reported in Table 3.

The emissivity of the furnace walls was set to 0.7 .

A mass flow rate condition was given to the primary duct inlet, whereas profiles of velocity components, turbulent characteristics as well as species concentration (computed from nonreactive runs on the complete domains) were given to the inlet section of the secondary and 
tertiary ducts. A pressure outlet condition was set for the furnace exit. As mentioned previously, a temperature profile was given to the furnace walls, whereas a heat extraction, available from measurements [17], was set for each cooling loop, thus treating them individually.

The second order upwind discretization scheme was applied for the spatial discretization. To help solution convergence, such a scheme was initialized on results obtained with a first order scheme. Convergence was ensured by all residuals below $10^{-5}$, except for the continuity equation for which residuals were of about $10^{-4}$. Moreover the stabilization of physical quantities was monitored at different location inside the furnace.

Typically, runs with EDC needed about 20 days to be completed using 32 processors, whereas EDM runs were much faster.

\section{Results}

\subsection{Verification of reduced domain}

Figure 6 shows the distribution of axial and tangential velocities, as well as turbulent kinetic energy, across the reduced domain inlet surfaces for the secondary and tertiary ducts. Such distributions were obtained from calculations on the complete domain. It can be noticed the strong 3D features for the flow field.

The reduced domain was verified through comparison of velocity profiles obtained at different axial distances $\mathrm{z}$ in the furnace with the completed domain for non-reactive tests(see scheme of Figure 5). Figure 7a and Figure $7 \mathrm{~b}$ show such comparison for the axial and tangential velocities, respectively. It can be noticed that the agreement is satisfactory, thus allowing operating with the reduced domain in order to decrease the computational time of about $30 \%$. 


\subsection{Effect of combustion model}

Figure $8 \mathrm{a}$ and Figure $8 \mathrm{~b}$ show the transverse distribution of temperature and $\mathrm{O}_{2}$ molar fraction (dry), respectively, within the furnace predicted with the EDC model and WDair scheme. It can be noticed the complex shape of the flame, which is generated from the TEA-C burner. The 3-dimensionality of the flame is well evident from the temperature distribution in cross sections of the furnaces corresponding to the first $(\mathrm{z}=0.17 \mathrm{~m})$ and second $(\mathrm{z}=0.46 \mathrm{~m})$ measuring ports (see Figure 9b and Figure 9d, respectively). The TEA-C burner generates a flame which is not axisymmetric, but varies with the angular coordinate, because of the peculiar injection of GN and oxidizer through three different nozzles. This angular dependence smoothers far away from the burner. Figure 9a and Figure 9c show the much different distributions obtained with the EDM model and for the same WDair scheme, thus highlighting the strong effect of the turbulence/chemistry interaction treatment on the temperature field.

Figure 10 compares the measured radial profiles of temperatures and $\mathrm{CO}_{2}$ with those predicted with the two different combustion models. It can be noticed that temperature experimental data at the first port $(\mathrm{z}=0.17 \mathrm{~m}$, see Figure 10a) show high temperatures for $\mathrm{r}=0.15-0.2 \mathrm{~m}$. Such peak temperatures are not detectable by the EDM combustion model, which predicts a low temperature region, the maximum temperature being of $1461 \mathrm{~K}$ for $\mathrm{r}=0.15-0.2 \mathrm{~m}$. This does not mean that EDM does not predict a flame front for $\mathrm{z}=0.17 \mathrm{~m}$, but rather than the flame front does not cross the horizontal plane corresponding to the insertion of the pyrometer in the furnace (see transverse contours of Figure 9a). However, even considering uncertainties in the measurements location by assuming that the suction pyrometer is not measuring precisely on the horizontal plane, but at maximum $2 \mathrm{~cm}$ far (according to the experimental experience) the poor performance of the EDM model cannot be justified [33]. The EDC 
model performs much better as it is able to correctly predict the temperature peaks in such a location, even though values are higher than measured ones for $r=0.15-0.2 \mathrm{~m}$. This could be imputed to the global mechanisms used in the present work which usually tend to overestimate the temperatures with respect to more complex schemes. The better performance of the EDC model is confirmed also by the error metrics of temperatures reported in the first and second columns of Table 4. The EDM model showed a relative error of $23.2 \%$ at $\mathrm{z}=0.17 \mathrm{~m}$ and of $14.7 \%$ globally, whereas the EDC model provided a relative error of $14.3 \%$ at $\mathrm{z}=0.17$ $\mathrm{m}$ and $10 \%$ globally. The same conclusions can be also drawn from the $\mathrm{CO}_{2}$ concentration profiles of Figure 10a. Only the EDC model is able to capture the measured $\mathrm{CO}_{2}$ peak at $\mathrm{r}=$ 0.15-0.2 m, and thus the $\mathrm{CO}_{2}$ trend (see also validation metrics reported in the first and second columns of Table 5).

At further distances (second port, $\mathrm{z}=0.46 \mathrm{~m}$ see Figure 10b), the EDM and the EDC model predictions are much closer. The EDM model estimates temperatures above of $2200 \mathrm{~K}$ for $\mathrm{r}=$ $0.18-0.3 \mathrm{~K}$, whereas the maximum experimental temperature in such a region is $2000 \mathrm{~K}$ (at $\mathrm{r}=$ $0.2 \mathrm{~m}$ ). The EDC model captures perfectly the temperature values for $\mathrm{r}=0.15,0.2$ and $0.3 \mathrm{~m}$ whereas it predicts higher values for $\mathrm{r}=0.25 \mathrm{~m}$. It could be desirable to have more experimental points as the distances between them may hidden the presence of experimental peaks in some locations; however it should be taken into account the difficulty in carrying out semi-industrial experimental campaigns. The $\mathrm{CO}_{2}$ radial profile at $\mathrm{z}=0.46 \mathrm{~m}$ indicated that the EDC model correctly predicts a concentration peak for $r=0.175 \mathrm{~m}$ and the trend for larger radial distances although some over prediction of $\mathrm{CO}_{2}$ concentration is observed for $\mathrm{r}=0.3$ $0.5 \mathrm{~m}$. Its performance is anyway superior to that of the EDM model as confirmed also by the absolute validation metrics, which were of $6.6 \%$ and $4 \%$ for the EDM and EDC model, respectively. 
At $\mathrm{z}=1.04 \mathrm{~m}$ (Figure 10c) the impact of the combustion model is less visible, with smaller differences between prediction with EDM and EDC. The temperature profiles are well captured except for the temperature measurement in the axis $(\mathrm{T}=1113 \mathrm{~K}$ for $\mathrm{r}=0)$ which is largely over-predicted by both models. The $\mathrm{CO}_{2}$ radial profile shows significant discrepancies although the trends are correct.

Finally at $\mathrm{z}=1.62 \mathrm{~m}$ (Figure 10d) EDM and EDC predict similar profiles which capture well the temperature measurements, indicating a proper energy balance in the furnace. The $\mathrm{CO}_{2}$ radial profile shows some significant discrepancies. However, such discrepancies were found to decrease for larger distances from the burner, indicating a correct air leakage evaluation through mass balances in the systems. It is worth noting that such agreement could not be achieved by performing the mass balance with different criteria, as for instance by minimizing the errors on just one species (e.g. $\left.\mathrm{O}_{2}\right)$ instead of both $\left(\mathrm{CO}_{2}\right.$ and $\left.\mathrm{O}_{2}\right)$.

\subsection{Effect of kinetic scheme}

The effect of kinetic schemes on the predictions is shown in Figure 11, which reports the comparison between measured radial profiles of temperature and $\mathrm{CO}_{2}$ and those predicted different kinetic schemes coupled to turbulence through the EDC model. As mentioned earlier, all schemes are global, as the large computational cost of the simulations prevented from using more complex kinetics. It can be noticed that the choice of the kinetic schemes affects strongly the predictions.

As for temperature, all models except for JLoxy, are able to capture trends. In particular at $\mathrm{z}=$ $0.17 \mathrm{~m}$ (Figure 11a) they correctly predict the presence and position of the temperature peak, as well as the decrease for temperature with a further increase of the radial distance. It can be also noticed how the modification of the WD scheme proposed by [5] is very effective in 
reducing the too high temperature peak predicted by the original WD global scheme. The $\mathrm{CO}_{2}$ concentration profiles indicate a better performance of the WDair and WDoxy schemes, as the JLair scheme detects low $\mathrm{CO}_{2}$ levels at $\mathrm{r}=0.2 \mathrm{~m}$, not noticed by the measurements. The JLoxy shows the worse predictions as proved by the validation metrics for temperature, $\mathrm{CO}_{2}$ and $\mathrm{O}_{2}$ (see Table 4, Table 5 and Table 6, respectively). Similar conclusions may be drawn from the comparison at $\mathrm{z}=0.46 \mathrm{~m}$ (Figure $11 \mathrm{~b}$ ).

With further distances $(\mathrm{z}=1.04 \mathrm{~m}$, see Figure 11b) the impact of the kinetic schemes on the temperature profiles is lower, indicating that the heat release is almost completed. However $\mathrm{CO}_{2}$ profiles show significant differences between predictions and measurements. The JLair and JLoxy schemes better capture the low $\mathrm{CO}_{2}$ levels at $\mathrm{r}=0.3 \mathrm{~m}$, whereas the WDair and WDoxy schemes perform better with increasing radial distances.

At $\mathrm{z}=1.62 \mathrm{~m}$ the temperature profiles are well predicted (except for the low temperature point at $\mathrm{r}=0$ ), whereas some discrepancies are found for $\mathrm{CO}_{2}$. The $\mathrm{CO}_{2}$ measurements are only well captured at the following measuring ports $(\mathrm{z}=3.84 \mathrm{~m})$, as evinced by the validation metrics of Table 5, indicating errors lower than $2.5 \%$.

The same conclusions may be drawn from the comparison of measured and predicted $\mathrm{O}_{2}$. The graphical comparison is not reported here, but the validation metrics for all models are given in Table 6.

$\mathrm{CO}$ measurements could not be exploited effectively as in many locations the measurements exceeded the upper threshold level of the instruments. Results seems to indicate that the better agreement was achieved with the revised version of WD, WDoxy, thus confirming the effectiveness of the revision proposed by [5] however further experimental data are needed for validate the kinetic schemes., standard WSGG model. 
shows the example of propagation of model uncertainty into predicted temperature profiles at two ports, illustrating also the temperature experimental uncertainty. Given the same turbulence/chemistry interaction model (EDC) the graphs show the effect of the choice of the kinetic scheme on the modeling results: it can be noticed the wide range of temperatures obtained with the different models. As for the temperature experimental uncertainties, these have been obtained by considering all possible sources of errors related to the use of the suction pyrometer (i.e. errors due to inefficient convective heat transfer; errors related to gas velocity, conduction and radiation; errors of the voltmeters and of the thermocouple; statistical errors). Details of the experimental uncertainty evaluation can be found in [21].

The graphs of Figure 12 give an idea of the importance of performing a hierarchical sensitivity analysis on different modelling issues: for instance it can be noticed how the low temperature data near the axis lies well outside of the range of predictions spanned by the different models, thus demanding for further explanation.

\subsection{Effect of spectral model}

The spectral model was also found to play an important role, indicating that this aspect should be addressed for the modeling of such semi-industrial tests. Figure 13 shows the comparison between experimental profiles of temperature and those predicted with the standard and revised WSGG spectral models, using the EDC combustion model and the WDair kinetic scheme. It can be noticed that the use of a revised WSGG for oxy-fuel conditions largely improves the temperature predictions near the furnace axis. In such a manner the low temperature region near the axis is well captured at $\mathrm{z}=0.17 \mathrm{~m}$ and $\mathrm{z}=0.46 \mathrm{~m}$. At $\mathrm{z}=1.02 \mathrm{~m}$ some under-prediction of temperature is observed, however results are much more in agreement than those obtained with the standard version of the WSGG. This is also well 
represented by the validation error metrics which show that the lowest deviation from experiments was achieved through the revised version of WSGG (see Table 4). We believe that further improvements could be achieved by adapting the WSGG polynomials to the real conditions of the present investigations.

\section{Discussion and conclusions}

Numerical simulations of a semi-industrial furnace equipped with a low NOx burner and operated in oxy-fired conditions have been performed trying to validate different sub-models. The validation procedure faces some criticism, when applied to semi-industrial devices, especially because the scale of the burner/furnace requires significantly demanding computational grid, so that efforts are needed in order to optimize the computational time. The validation approach followed herein demonstrated that uncertainties due to the choice of different sub-models and boundary conditions are greater than experimental uncertainties.

Other issues regard some uncertainties related to air leakage which unavoidably occurs when retro-fitting existing air-fired furnaces for oxy-fuel combustion. Provided that the amount of air leakage can be reconstructed from available measurements on the flue gas composition by performing a mass balance, the location of the air leakage cannot be known precisely and has to be assumed.

The work has shown that the turbulence/chemistry interaction treatment plays a major role in determining the temperature and species fields, thus indicating the inadequacy of fast chemistry approaches. The Eddy Dissipation Concept was found to provide satisfactory predictions of the temperature and major species field. Oxidation mechanisms, here addressed only through global schemes, are also found to affect considerably predictions; however a precise conclusion on the superiority of one scheme may be not drawn as the $\mathrm{CO}$ 
measurements could not be fully exploited. So far, slightly better results seem to be obtained with the WD scheme modified for oxy-fuel conditions, whereas the JL schemes show larger discrepancies. However it should be pointed out that a revision of the global mechanism should be made by taking into consideration the specific conditions of the present runs, which were characterized by a strong air leakage, thus by the presence of a non-negligible amount of $\mathrm{N}_{2}$ in the reaction region.

Finally, a strong influence of the spectral model was observed: only a revised version for oxyfuel condition was found to be able to capture a low temperature region near the furnace axis, although the WSGG model should be optimized for the precise conditions of the present oxyfuel experiments. Therefore it is recommended to use spectral modes suited for oxy-fuel conditions especially when dealing with large scale furnaces.

Future work will concentrate on the revision of kinetic schemes for the specific conditions of the present investigations and on predictions of NO emissions.

\section{Acknowledgments:}

We would like to thank Ing. A. Rallo and S. Pelagallo who carried out a large part of the computational runs. 


\section{References}

[1] Wall T, Liu Y, Spero C, Elliott L, Khare S, Rathnam R, Zeenathal F, Moghtaderi B, Buhre B, Sheng C, Gupta R, Yamada T, Makino J, Yu J. An overview on oxyfuel coal combustionState of the art research and technology development. Chem Eng Res Des 2009;87:1003-1016. [2] Toftegaard MB, Brix J, Jensen PA, Glarborg P, Jensen AD. Oxy-fuel combustion of solid fuels. Progr Energy Comb Science 2010; 36: 581-625.

[3] Chen L, Zheng Yong S, Ghoniem AF. Oxy-fuel combustion of pulverized coal: Characterization, fundamentals, stabilization and CFD modeling. Progr Energy Comb Science 2012; 38: 156-214.

[4] Glarborg P, Bentzen LLB. Chemical effects of a high CO2 concentration in oxy-fuel combustion of methane. Energy Fuels 2008;22:291-296.

[5] Andersen J, Rasmussen CL, Giselsson T, Glarborg P. Global combustion mechanisms for use in CFD modeling under oxy-fuel conditions. Energy Fuels 2009;23:1279-1389.

[6] Westbrook CK, Dryer FK. Simplified reaction mechanisms for the oxidation of hydrocarbon. Combust Sci Technol 1981;27: 31-43.

[7] Jones WP, Lindstedt RP. Global reaction schemes for hydrocarbon combustion. Combust Flame 1988;73:233-49.

[8] Frassoldati A, Cuoci A, Faravelli T, Ranzi E, Candusso C, Tolazzi D, Simplified kinetic schemes for oxy-fuel combustion. 1st Int. Conf. on Sustainable Fossil Fuels for Future Energy - S4FE (2009) Rome, Italy.

[9] Smith F, Shen ZF, Friedman JN. Evaluation of coefficients for the weighted sum of gray gases model. J Heat Transfer 1982; 104:602-8. 

based radiative transfer in large air-fired and oxy-fired furnaces, Coal technology association, Sheraton Sand Key, Clearwater, FL, USA, 2006

$$
\text { Wang L, Endrud NE, Turns SR, D’Agostini MD, Slavejkov AG. A study of }
$$

the influence of oxygen index on soot, radiation, and emission characteristics of turbulent jet flames. Combust Sci Technol 2002;174:45-72.

Andersson K, Johansson R, Johnsson F, Leckner B. Radiation intensity of propane-fired oxy-fuel flames: Implications for soot formation. Energy Fuels 2008;22:153541.

Johansson R, Andersson K, Leckner B, Thunman H, Models for gaseous radiative heat transfer applied to oxy-fuel conditions in boilers. Int $\mathbf{J}$ Heat Mass Trans 2010;53: 220-230.

Ströhle J. Wide band correlated-k approaches for non-grey radiation modelling in oxy-fuel combustion with dry recycling. Fuel 2011; 90:3007-3013

Yin C, Johansen LCR, Rosendahl LA, Kær SK. New Weighted Sum of Gray Gases model applicable to Computational Fluid Dynamics (CFD) modeling of oxy-fuel Combustion: derivation, validation, and implementation. Energy Fuels 2010;24:6275-6282.

[16] Yin C, Rosendahl LA, Kær SK. Chemistry and radiation in oxy-fuel combustion: A computational fluid dynamics modeling study. Fuel 2011;90:2519-2529. Coraggio G, Laiola M. Combustion of NG and pulverised coal in a mixture of oxygen and RFG. IFRF Report n. F110/y/01, 2009.

$$
\text { Coraggio G, Tognotti L, Cumbo D, Rossi N, Brunetti J. Retrofitting oxy- }
$$
fuel technology in a semi-industrial plant: Flame characteristics and NOx production from a low NOx burner fed with natural gas. Proc Comb Inst 2011;33:3423-3430. 
Förster M, Kneer R. Detailed investigation of a pulverized fuel swirl flame in $\mathrm{CO}_{2} / \mathrm{O}_{2}$ atmosphere. Combust Flame 2008; 155:605-618.

Weber R, Peters AAF, Breithaupt PP, Visser BM. Mathematical modeling of swirling flames of pulverized coal: What can combustion engineers expect from modeling?. J Fluids Engineering 1995;117: 289-297.

Parente A, Coraggio G, Galletti C, Tognotti L. Verification, validation and uncertainties quantification in industrial combustion modelling: some practical tools. IFRF Report n. G25/y/01, 2011.

Oberkampf WL, Trucano TG. Validation in Computational Fluid Dynamics. Prog Aerosp Sci 2002;38:209-272.

Galletti C, Parente A, Coraggio G, Tognotti L. Estimation of uncertainties in experimental data and model predictions for a semi-industrial furnace. IFRF Members Conference, vol. 16, Boston, 2009. Menter FR. Two-equation eddy-viscosity turbulence models for engineering applications. AIAA Journal 1994;32:1598-1605.

$$
\text { Chen L, Ghoniem AF. Simulation of oxy-coal combustion in a } 100 \mathrm{kWth}
$$

test facility using RANS and LES: a validation study. Energy Fuels 2012;26:4783-4798.

$$
\text { Peters AAF, Weber R. Mathemathical Modeling of a } 2.4 \text { MW swirling }
$$
pulverized coal flame. Comb Sci Tech 1997;172:131-182.

$$
\text { Oberkampf WL, Barone MF. Measures of agreement between computation }
$$
and experiment: validation metrics, J Comp Physics 2006;217: 5-38.

$$
\text { Weber R, Dugue J. Combustion accelerated swirling flows in high }
$$
confinements. Prog Energ Combust Science 1972;18:349-367. 

combustion with special emphasis on soot formation. Proc Combust Inst 1976;16: 719-29. dissipation concept for chemical reaction in turbulent flow. In: 19th AIAA aerospace science meeting, St. Louis, Missouri; 1981.

Pope SB. Computationally efficient implementation of combustion chemistry using in situ adaptive tabulation. Comb Theory Model 1997; 1:44-63.

Combust Flame 1983; 49:101-8.ù

Galletti C, Modesti A, Pelagallo S, Brunetti I, Rossi N, Tognotti L. Validation of oxy-combustion modelling via semi-industrial furnace tests. In: Proceedings of PTSE. Ischia, Italy, June 2010. 


\section{List of tables}

Table 1 - Operating conditions for oxy-NG runs [17].

Table 2 - Kinetic mechanisms WD [6] and JL [7], and revised versions WDoxy and JLoxy [5].

Units are in cm, s, cal, mol.

Table 3 - Constants of the 1-clear/3-gray gases WSGG model by [13].

Table 4 - Error metrics (average relative error), $\left|\frac{\tilde{E}}{\bar{y}_{e}}\right|_{\text {avg }}[\%]$, of temperature, evaluated globally and for each measuring port, as obtained with different sub-models.

Table 5 - Error metrics (average relative error), ${ }^{|\tilde{E}|_{\text {avg }}[\%]}$, of $\mathrm{CO}_{2}$, evaluated globally and for each measuring port, as obtained with different sub-models.

Table 6 - Error metrics (average relative error), ${ }^{|\tilde{E}|_{\text {avg }}[\%]}$, of $\mathrm{O}_{2}$, evaluated globally and for each measuring port, as obtained with different sub-models. 


\section{Figure captions}

Figure 1 - (a) FoSper furnace and (b) TEA-C burner.

Figure 2 - FoSper plant: dashed line: recycled gas line; dotted/dashed line: oxygen line.

Figure 3 - Surfaces used to cut the complete domain, corresponding to secondary (blue) and tertiary (red) duct inlets for the reduced domain.

Figure 4 - Details of the grids for the (b) complete and (c) reduced domains.

Figure 5 - Validation program for oxy-NG combustion tests in FoSper furnace.

Figure 6 - Distribution (calculated from complete domain simulations) across the secondary and tertiary duct inlets for the reduced domain, of (a) axial velocity (m/s), (b) tangential velocity $(\mathrm{m} / \mathrm{s})$ and $(b)$ turbulent kinetic energy $\left(\mathrm{m}^{2} / \mathrm{s}^{2}\right)$.

Figure 7 - Comparison of axial (a) and tangential (b) velocity profiles predicted at different distances $\mathrm{z}$ from the burner quarl using the reduced and complete domains.

Figure 8 - (a) Temperature $\mathrm{T}(\mathrm{K})$ and (b) $\mathrm{O}_{2}$ concentration (\% vol. dry) along the horizontal plane of the furnace. Solid lines indicates the location of first $(z=0.17 \mathrm{~m})$, second $(z=0.46$ $\mathrm{m})$, fourth $(\mathrm{z}=1.04 \mathrm{~m})$ and sixth $(\mathrm{z}=1.62 \mathrm{~m})$ measuring ports. EDC combustion model, WDair kinetic scheme, standard WSGG model.

Figure 9 - Temperature distribution $\mathrm{T}(\mathrm{K})$ in cross sections of the furnace corresponding to (ab) first $(z=0.17 \mathrm{~m})$ and $(\mathrm{c}-\mathrm{d})$ second $(\mathrm{z}=0.46 \mathrm{~m})$ measuring ports obtained with: (a-c) EDM and (b-d) EDC combustion models. WDair kinetic scheme, standard WSGG model. 
Figure 10 - Comparison between experimental temperature and $\mathrm{CO}_{2}$ concentration and those predicted with EDM and EDC combustion model at different measuring ports: (a) $\mathrm{z}=0.17 \mathrm{~m}$; (b) $\mathrm{z}=0.46 \mathrm{~m}$; (c) $\mathrm{z}=1.04 \mathrm{~m}$; (d) $\mathrm{z}=1.62 \mathrm{~m}$. WDair kinetic scheme, standard WSGG model. Figure 11 - Comparison between experimental temperature and $\mathrm{CO} 2$ concentration and those predicted with different kinetic schemes at different measuring ports: (a) $\mathrm{z}=0.17 \mathrm{~m}$; (b) $\mathrm{z}=$ $0.46 \mathrm{~m} ;(\mathrm{c}) \mathrm{z}=1.04 \mathrm{~m} ;$ (d) z = $1.62 \mathrm{~m}$. EDC combustion model, standard WSGG model.

Figure 12 - Propagation of model uncertainty into predicted temperature profiles (EDC model and different kinetic schemes, standard WSGG model) at (a) port $2(\mathrm{z}=0.46) \mathrm{m}$ and (b) port 4 $(z=1.04 \mathrm{~m})$ : error bars represent experimental uncertainties of local mean temperatures.

Figure 13 - Comparison between experimental temperature and that predicted with standard and revised WSGG model at different measuring ports: (a) $\mathrm{z}=0.17 \mathrm{~m}$; (b) $\mathrm{z}=0.46 \mathrm{~m}$; (c) $\mathrm{z}=$ $1.04 \mathrm{~m} ;$ (d) z = $1.62 \mathrm{~m}$. EDC combustion model, WDair kinetic scheme. 


\begin{tabular}{|l|c|}
\hline NG flow rate & $267 \mathrm{Nm}^{3} / \mathrm{h}$ \\
NG temperature & $14.3^{\circ} \mathrm{C}$ \\
Oxygen & $730 \mathrm{~kg} / \mathrm{h}$ \\
Oxygen temperature & $15.3^{\circ} \mathrm{C}$ \\
Primary RFG & $700 \mathrm{~kg} / \mathrm{h}$ \\
PrimaryRFG temperature & $125^{\circ} \mathrm{C}$ \\
Secondary/tertiary RFG & $1447 \mathrm{~kg} / \mathrm{h}$ \\
Secondary/tertiary RFG & $250^{\circ} \mathrm{C}$ \\
temperature & $0-100 \%$ \\
Swirler setting & $100-100 \%$ \\
Dumper setting & 0.69 \\
Recycle ratio & $2.7 \mathrm{MW}$ \\
Fuel thermal input & $1050^{\circ} \mathrm{C}$ \\
Flue gas temperature & $1.186 \mathrm{MW}$ \\
Total heat extracted & $3.2 \%$ \\
$\mathrm{O}_{2}$ in flue gas & $11 \mathrm{ppm}$ \\
$\mathrm{CO}_{\text {in flue gas }}$ & $68.7 \%$ \\
$\mathrm{CO}_{2}$ in flue gas & $120 \mathrm{ppm}$ \\
$\mathrm{NO}_{\mathrm{x}}$ in flue gas & \\
\hline
\end{tabular}




\begin{tabular}{|c|c|c|c|c|c|}
\hline Mechanism & Reactions & A & $\beta$ & $\mathrm{E}_{\mathrm{a}}$ & Reaction order \\
\hline WD [6] & $\begin{array}{l}\mathrm{CH}_{4}+1.5 \mathrm{O}_{2}=>\mathrm{CO}+2 \mathrm{H}_{2} \mathrm{O} \\
\mathrm{CO}+0.5 \mathrm{O}_{2}=>\mathrm{CO}_{2} \\
\mathrm{CO}_{2}=>\mathrm{CO}+0.5 \mathrm{O}_{2}\end{array}$ & $\begin{array}{l}1.59 \cdot 10^{13} \\
3.98 \cdot 10^{14} \\
6.16 \cdot 10^{13}\end{array}$ & $\begin{array}{l}0 \\
0 \\
0\end{array}$ & $\begin{array}{l}47800 \\
40700 \\
40700\end{array}$ & $\begin{array}{c}{\left[\mathrm{CH}_{4}\right]^{0.7}\left[\mathrm{O}_{2}\right]^{0.8}} \\
{[\mathrm{CO}]\left[\mathrm{O}_{2}\right]^{0.25}\left[\mathrm{H}_{2} \mathrm{O}\right]^{0.5}} \\
{\left[\mathrm{CO}_{2}\right]}\end{array}$ \\
\hline WDoxy [5] & $\begin{array}{l}\mathrm{CH}_{4}+1.5 \mathrm{O}_{2}=>\mathrm{CO}+2 \mathrm{H}_{2} \mathrm{O} \\
\mathrm{CO}+0.5 \mathrm{O}_{2}=>\mathrm{CO}_{2} \\
\mathrm{CO}_{2}=>\mathrm{CO}+0.5 \mathrm{O}_{2}\end{array}$ & $\begin{array}{l}1.59 \cdot 10^{13} \\
3.98 \cdot 10^{8} \\
6.16 \cdot 10^{13}\end{array}$ & $\begin{array}{c}0 \\
0 \\
-0.97\end{array}$ & $\begin{array}{l}47800 \\
10000 \\
78400\end{array}$ & $\begin{array}{c}{\left[\mathrm{CH}_{4}\right]^{0.7}\left[\mathrm{O}_{2}\right]^{0.8}} \\
{[\mathrm{CO}]\left[\mathrm{O}_{2}\right]^{0.25}\left[\mathrm{H}_{2} \mathrm{O}\right]^{0.5}} \\
{\left[\mathrm{CO}_{2}\right]\left[\mathrm{H}_{2} \mathrm{O}\right]^{0.5}\left[\mathrm{O}_{2}\right]^{-0.25}}\end{array}$ \\
\hline JL [7] & $\begin{array}{l}\mathrm{CH}_{4}+0.5 \mathrm{O}_{2}=>\mathrm{CO}+2 \mathrm{H}_{2} \\
\mathrm{CH}_{4}+\mathrm{H}_{2} \mathrm{O}=>\mathrm{CO}+3 \mathrm{H}_{2} \\
\mathrm{H}_{2}+0.5 \mathrm{O}_{2}<=>\mathrm{H}_{2} \mathrm{O} \\
\mathrm{CO}+\mathrm{H}_{2} \mathrm{O} \Leftrightarrow=>\mathrm{CO}_{2}+\mathrm{H}_{2}\end{array}$ & $\begin{array}{l}7.82 \cdot 10^{13} \\
3.00 \cdot 10^{11} \\
4.45 \cdot 10^{18} \\
2.75 \cdot 10^{12}\end{array}$ & $\begin{array}{c}0 \\
0 \\
-1 \\
0\end{array}$ & $\begin{array}{l}30000 \\
30000 \\
40000 \\
20000\end{array}$ & $\begin{array}{c}{\left[\mathrm{CH}_{4}\right]^{0.5}\left[\mathrm{O}_{2}\right]^{1.25}} \\
{\left[\mathrm{CH}_{4}\right]\left[\mathrm{H}_{2} \mathrm{O}\right]} \\
{\left[\mathrm{H}_{2}\right]^{0.5}\left[\mathrm{O}_{2}\right]^{2.25}\left[\mathrm{H}_{2} \mathrm{O}\right]^{-1}} \\
{[\mathrm{CO}]\left[\mathrm{H}_{2} \mathrm{O}\right]}\end{array}$ \\
\hline JLoxy [5] & $\begin{array}{l}\mathrm{CH}_{4}+0.5 \mathrm{O}_{2}=>\mathrm{CO}+2 \mathrm{H}_{2} \\
\mathrm{CH}_{4}+\mathrm{H}_{2} \mathrm{O}=>\mathrm{CO}+3 \mathrm{H}_{2} \\
\mathrm{H}_{2}+0.5 \mathrm{O}_{2}=>\mathrm{H}_{2} \mathrm{O} \\
\mathrm{H}_{2} \mathrm{O}=>\mathrm{H}_{2}+0.5 \mathrm{O}_{2} \\
\mathrm{CO}+\mathrm{H}_{2} \mathrm{O}<=>\mathrm{CO}_{2}+\mathrm{H}_{2}\end{array}$ & $\begin{array}{l}.82 \cdot 10^{13} \\
3.00 \cdot 10^{11} \\
5.00 \cdot 10^{20} \\
2.93 \cdot 10^{20} \\
2.75 \cdot 10^{12} \\
\end{array}$ & $\begin{array}{c}0 \\
0 \\
-1 \\
-0.877 \\
0 \\
\end{array}$ & $\begin{array}{l}30000 \\
30000 \\
30000 \\
97900 \\
20000 \\
\end{array}$ & $\begin{array}{c}{\left[\mathrm{CH}_{4}\right]^{0.5}\left[\mathrm{O}_{2}\right]^{1.25}} \\
{\left[\mathrm{CH}_{4}\right]\left[\mathrm{H}_{2} \mathrm{O}\right]} \\
{\left[\mathrm{H}_{2}\right]^{0.25}\left[\mathrm{O}_{2}\right]^{1.25}} \\
{\left[\mathrm{H}_{2}\right]^{-0.75}\left[\mathrm{O}_{2}\right]\left[\mathrm{H}_{2} \mathrm{O}\right]} \\
{[\mathrm{CO}]\left[\mathrm{H}_{2} \mathrm{O}\right]} \\
\end{array}$ \\
\hline
\end{tabular}




\section{Table 3}

\begin{tabular}{|l|c|c|c|c|}
\hline $\mathrm{i}$ & 1 & 2 & 3 & 4 \\
\hline$\kappa_{i}$ & 0.0408 & 0.4217 & 5.2010 & 122.48 \\
\hline $\mathrm{b}_{1}$ & 0.2719 & 0.3677 & 0.2324 & 0.1058 \\
\hline $\mathrm{b}_{2}$ & 0.0896 & -0.1284 & -0.1214 & -0.0602 \\
\hline $\mathrm{b}_{3}$ & -0.0327 & -0.0030 & 0.0170 & 0.0080 \\
\hline
\end{tabular}




\begin{tabular}{|l|c|c|c|c|c|c|}
\hline & $\begin{array}{c}\text { EDM } \\
\text { WDair } \\
\text { WSGG }\end{array}$ & $\begin{array}{c}\text { EDC } \\
\text { WDair } \\
\text { WSGG }\end{array}$ & $\begin{array}{c}\text { EDC } \\
\text { WDoxy } \\
\text { WSGG }\end{array}$ & $\begin{array}{c}\text { EDC } \\
\text { JLair } \\
\text { WSGG }\end{array}$ & $\begin{array}{c}\text { EDC } \\
\text { JLoxy } \\
\text { WSGG }\end{array}$ & $\begin{array}{c}\text { EDC } \\
\text { WDair } \\
\text { WSGGoxy }\end{array}$ \\
\hline Port1 $(\mathrm{z}=0.17 \mathrm{~m})$ & 23.2 & 14.3 & 14.7 & 11.0 & 27.9 & 13 \\
Port2 $(\mathrm{z}=0.46 \mathrm{~m})$ & 12.7 & 12.3 & 14.1 & 10.3 & 12.7 & 8.5 \\
Port4 $(\mathrm{z}=1.02 \mathrm{~m})$ & 6.2 & 7.3 & 8.3 & 7.4 & 6.9 & 5.6 \\
Port6 $(\mathrm{z}=1.64 \mathrm{~m})$ & 2.8 & 3.0 & 2.6 & 3.1 & 3.8 & 4.8 \\
\hline Average (all ports) & 12.8 & 10.2 & 11.0 & 9.3 & 15.3 & 8.7 \\
\hline
\end{tabular}




\begin{tabular}{|l|c|c|c|c|c|c|}
\hline & $\begin{array}{c}\text { EDM } \\
\text { WDair } \\
\text { WSGG }\end{array}$ & $\begin{array}{c}\text { EDC } \\
\text { WDair } \\
\text { WSGG }\end{array}$ & $\begin{array}{c}\text { EDC } \\
\text { WDoxy } \\
\text { WSGG }\end{array}$ & $\begin{array}{c}\text { EDC } \\
\text { JLair } \\
\text { WSGG }\end{array}$ & $\begin{array}{c}\text { EDC } \\
\text { JLoxy } \\
\text { WSGG }\end{array}$ & $\begin{array}{c}\text { EDC } \\
\text { WDair } \\
\text { WSGGoxy }\end{array}$ \\
\hline Port1 $(\mathrm{z}=0.17 \mathrm{~m})$ & 8.0 & 3.6 & 5.7 & 9.1 & 9.7 & 5.1 \\
Port2 $(\mathrm{z}=0.46 \mathrm{~m})$ & 6.6 & 4 & 8.4 & 3.5 & 5.1 & 7.3 \\
Port4 $(\mathrm{z}=1.02 \mathrm{~m})$ & 6.3 & 5.8 & 5.8 & 2.2 & 9.0 & 6.0 \\
Port6 $(\mathrm{z}=1.64 \mathrm{~m})$ & 5.9 & 7 & 4.7 & 2.8 & 10.4 & 4.4 \\
Port10 ( $=3.84 \mathrm{~m})$ & 2.4 & 1.1 & 2.4 & 1.6 & 3 & 2.5 \\
Port14 (z=6.2m) & 2.4 & 0.6 & 2.5 & 0.6 & 8.6 & 2.8 \\
\hline Average (all ports) & 5.6 & 4.2 & 5.9 & 7.3 & 8.0 & 5.4 \\
\hline
\end{tabular}




\begin{tabular}{|l|c|c|c|c|c|c|}
\hline & $\begin{array}{c}\text { EDM } \\
\text { WDair } \\
\text { WSGG }\end{array}$ & $\begin{array}{c}\text { EDC } \\
\text { WDair } \\
\text { WSGG }\end{array}$ & $\begin{array}{c}\text { EDC } \\
\text { WDoxy } \\
\text { WSGG }\end{array}$ & $\begin{array}{c}\text { EDC } \\
\text { JLair } \\
\text { WSGG }\end{array}$ & $\begin{array}{c}\text { EDC } \\
\text { JLoxy } \\
\text { WSGG }\end{array}$ & $\begin{array}{c}\text { EDC } \\
\text { WDair } \\
\text { WSGGoxy }\end{array}$ \\
\hline Port1 $(\mathrm{z}=0.17 \mathrm{~m})$ & 9.9 & 5.0 & 6.6 & 4.5 & 12.1 & 4.3 \\
Port2 $(\mathrm{z}=0.46 \mathrm{~m})$ & 5.9 & 3.9 & 4.2 & 3.5 & 5.5 & 4.5 \\
Port4 $(\mathrm{z}=1.02 \mathrm{~m})$ & 2.5 & 2.0 & 1.6 & 2.2 & 3.3 & 1.8 \\
Port6 $(\mathrm{z}=1.64 \mathrm{~m})$ & 3.0 & 2.7 & 2.3 & 2.8 & 3.4 & 2.3 \\
Port10 $(\mathrm{z}=3.84 \mathrm{~m})$ & 2.6 & 1.3 & 1.5 & 1.6 & 2.4 & 1.7 \\
Port14 (z=6.2m) & 0.9 & 0.8 & 1.7 & 0.6 & 2.2 & 0.8 \\
\hline Average (all ports) & 6.3 & 3.4 & 3.8 & 3.2 & 6.4 & 3.3 \\
\hline
\end{tabular}




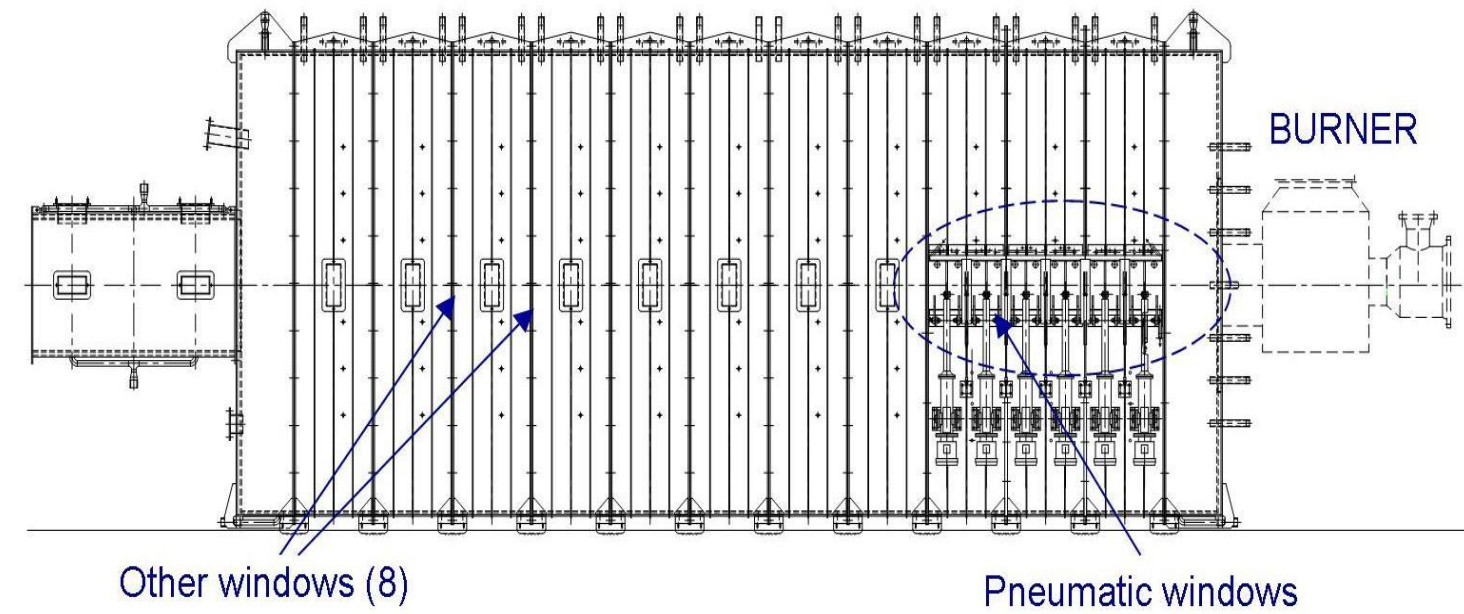

(a)

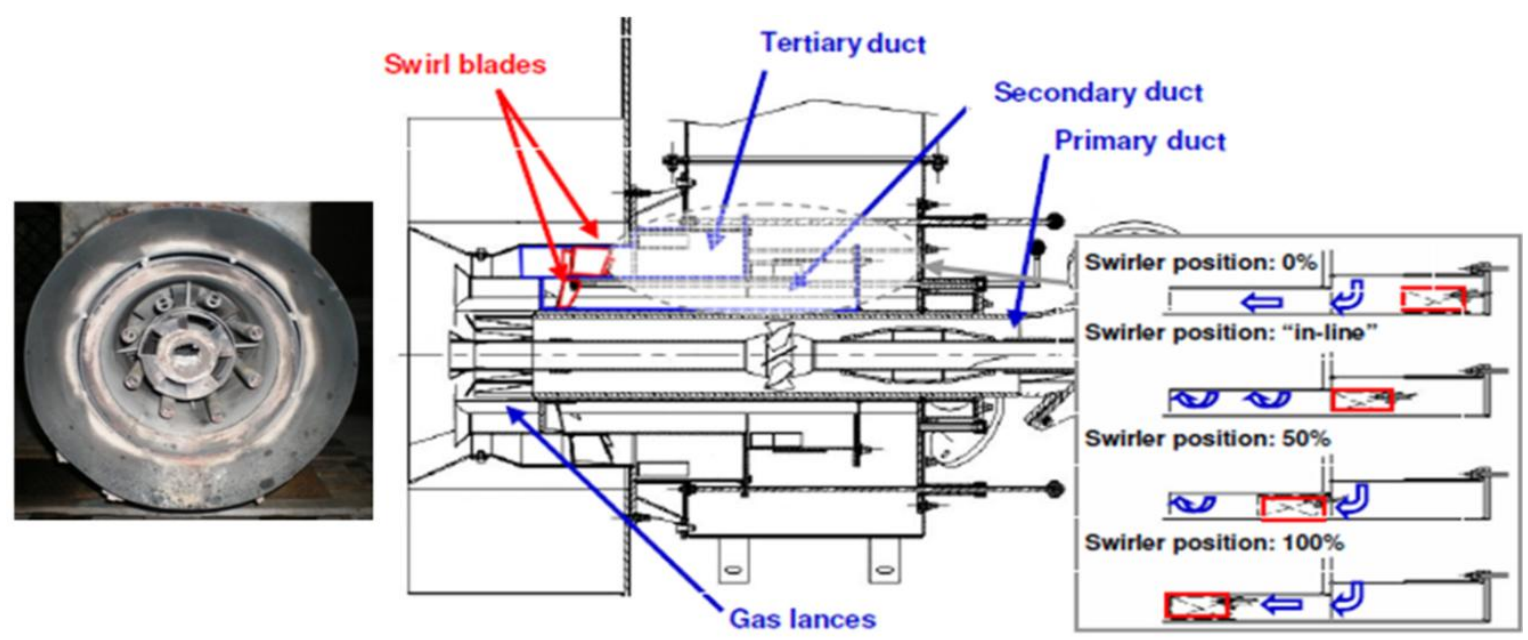

(b) 
Figure 2

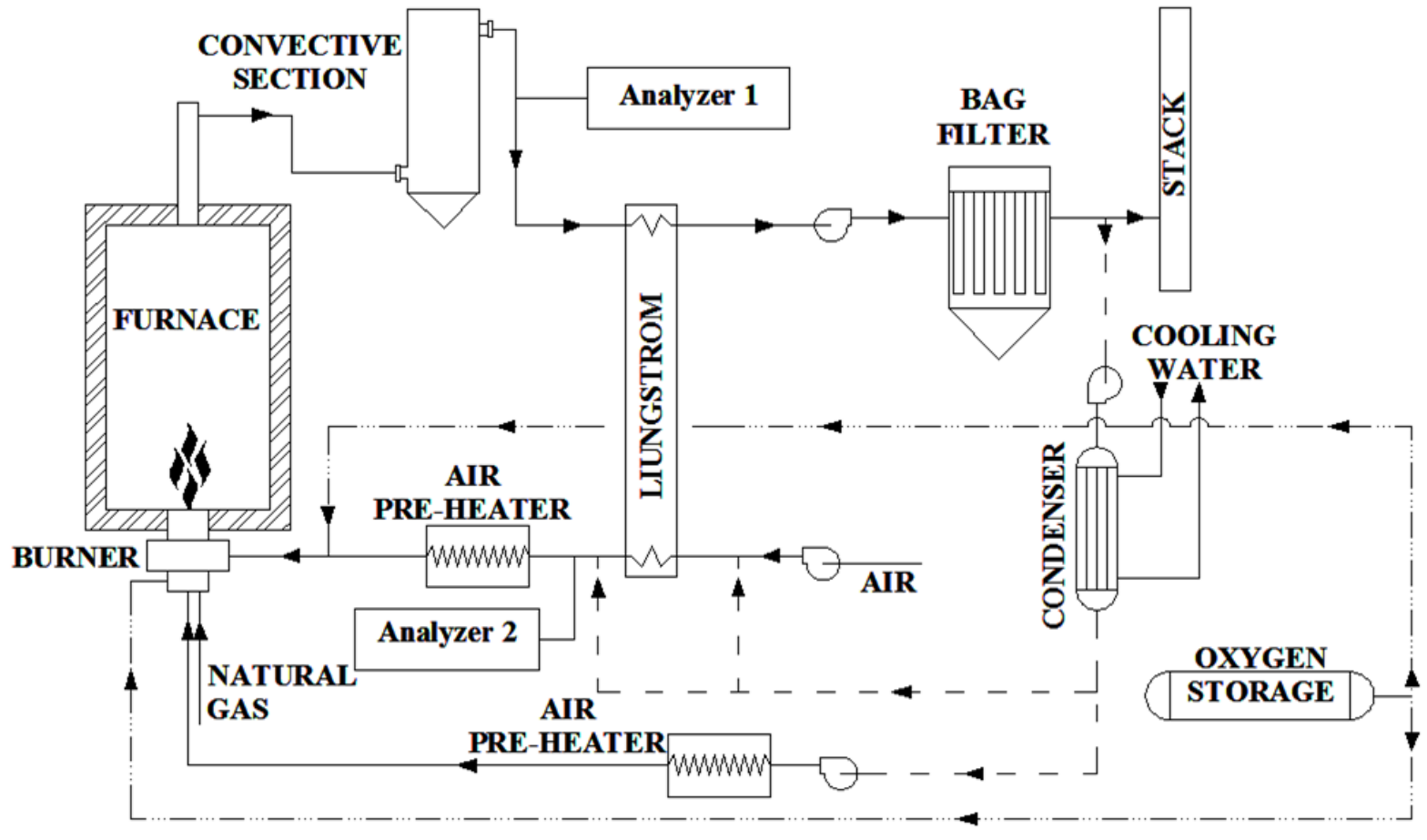




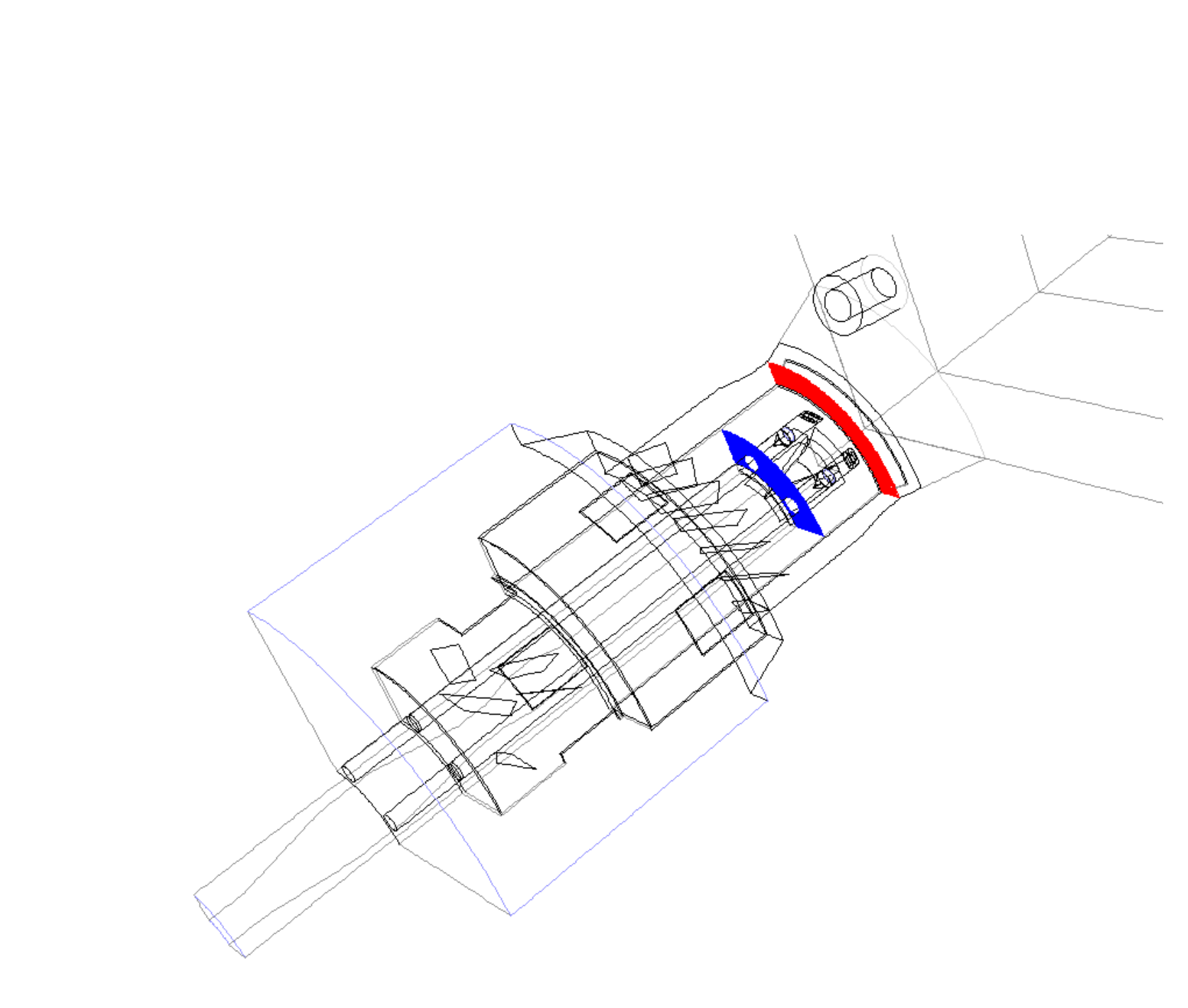

Figure 3

Figure 3
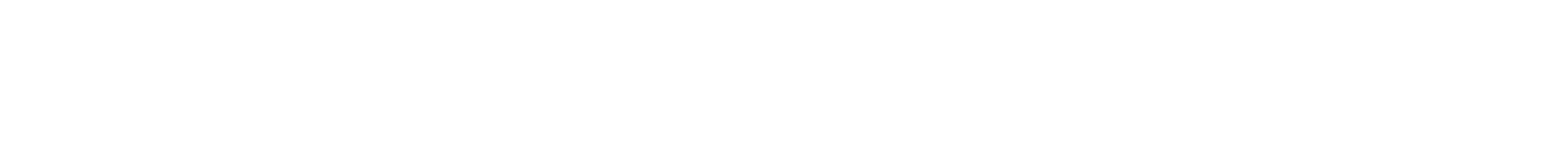

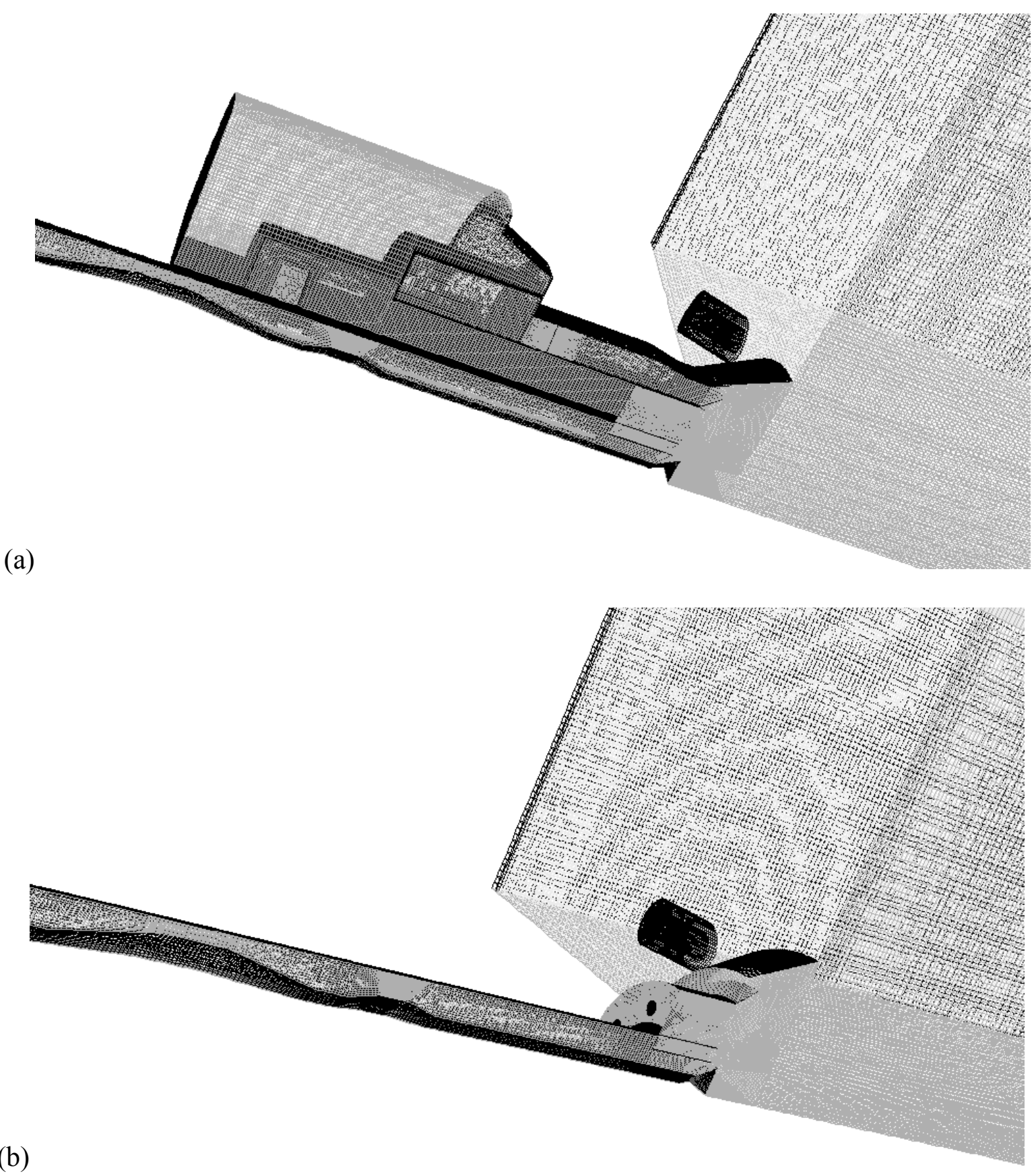

(b) 


\begin{tabular}{|l|c|}
\hline $\begin{array}{c}\text { (1) ISOTHERMAL TESTS } \\
\begin{array}{c}\text { BCs at inlets from isothermal } \\
\text { experimental tests with air }\end{array}\end{array}$ & $\begin{array}{c}\text { CFD model \#1 } \\
\text { - Complete burner+furnace } \\
\text { - Turbulence model }\end{array}$ \\
\hline
\end{tabular}

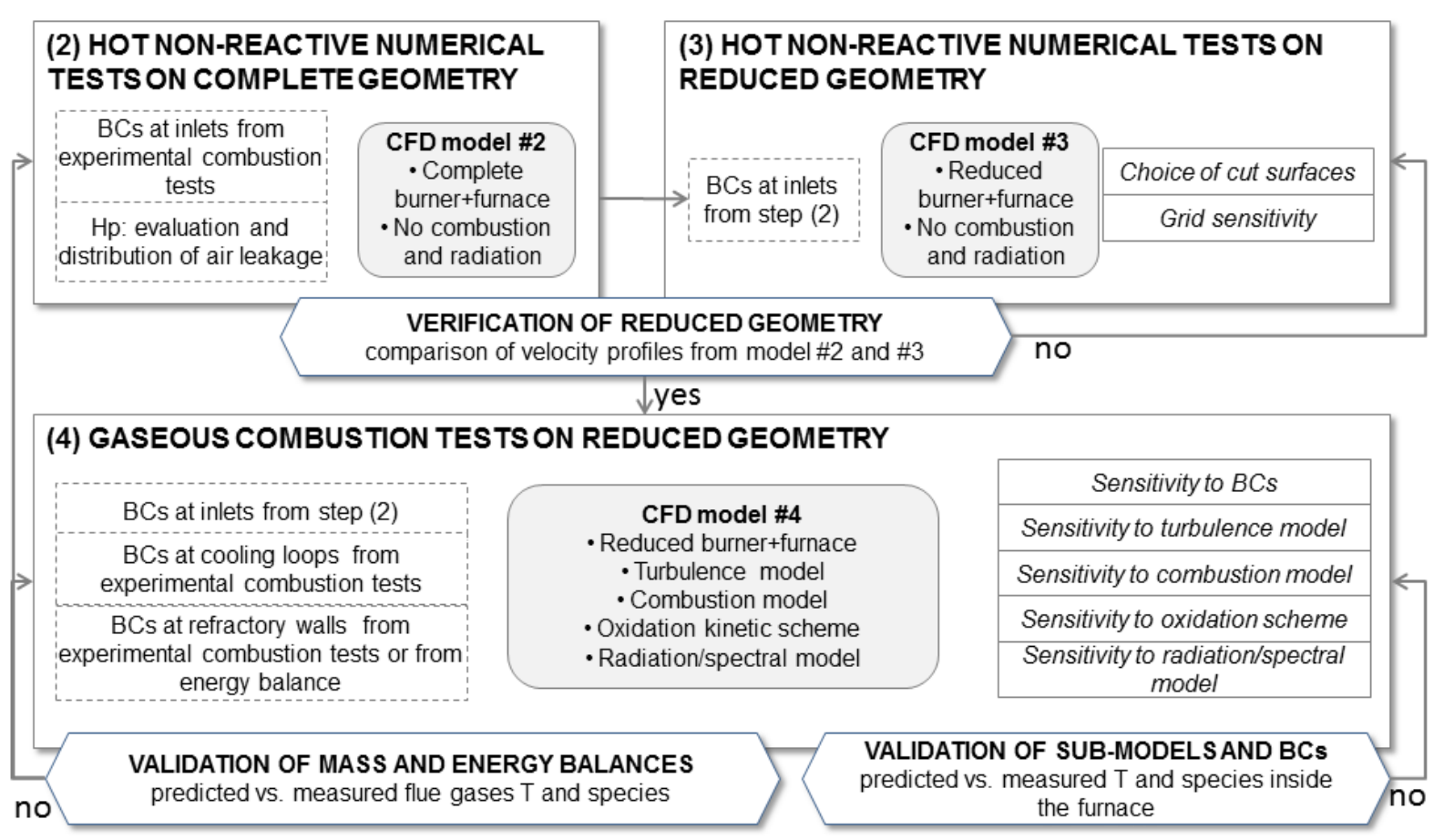




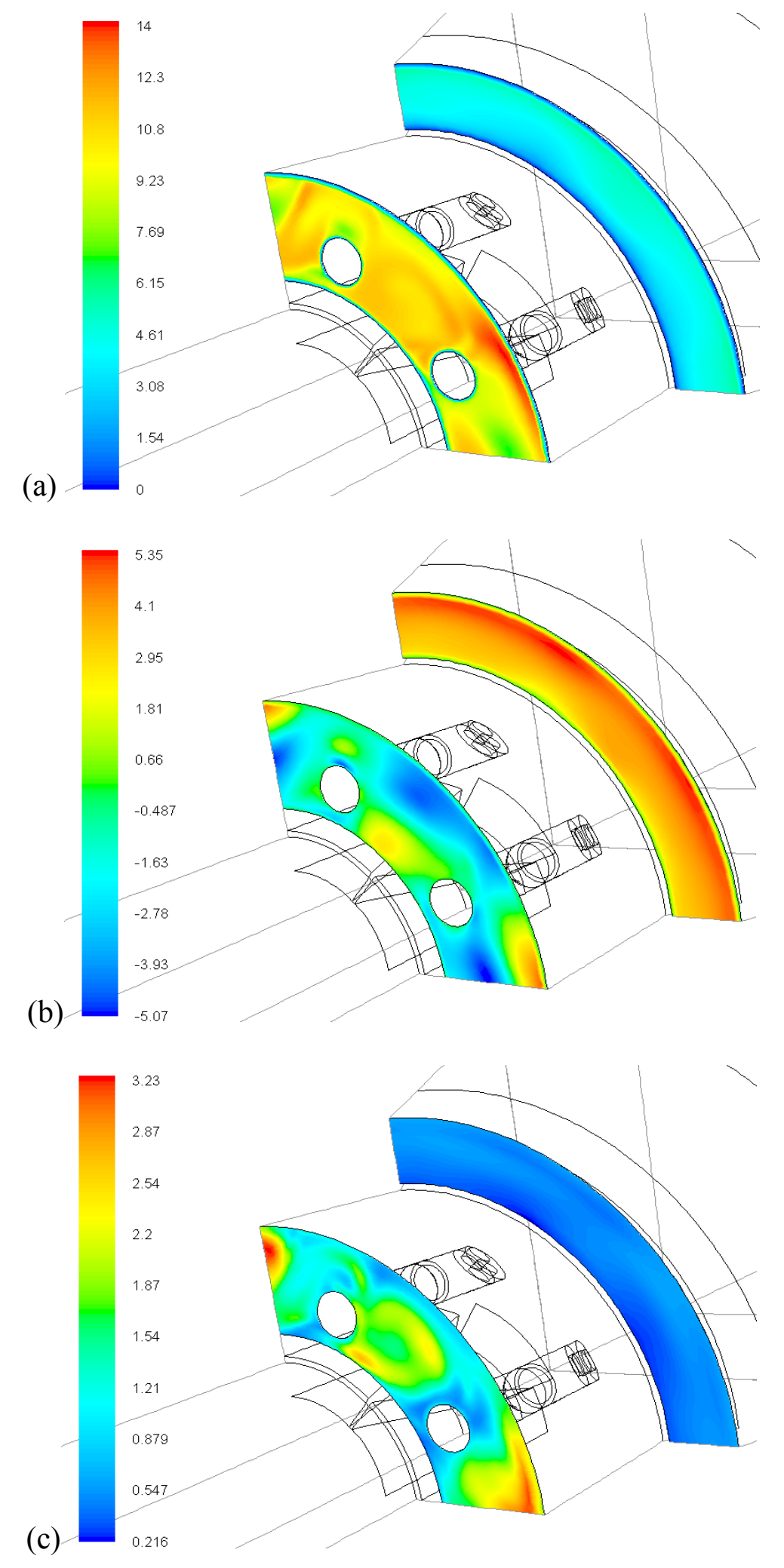



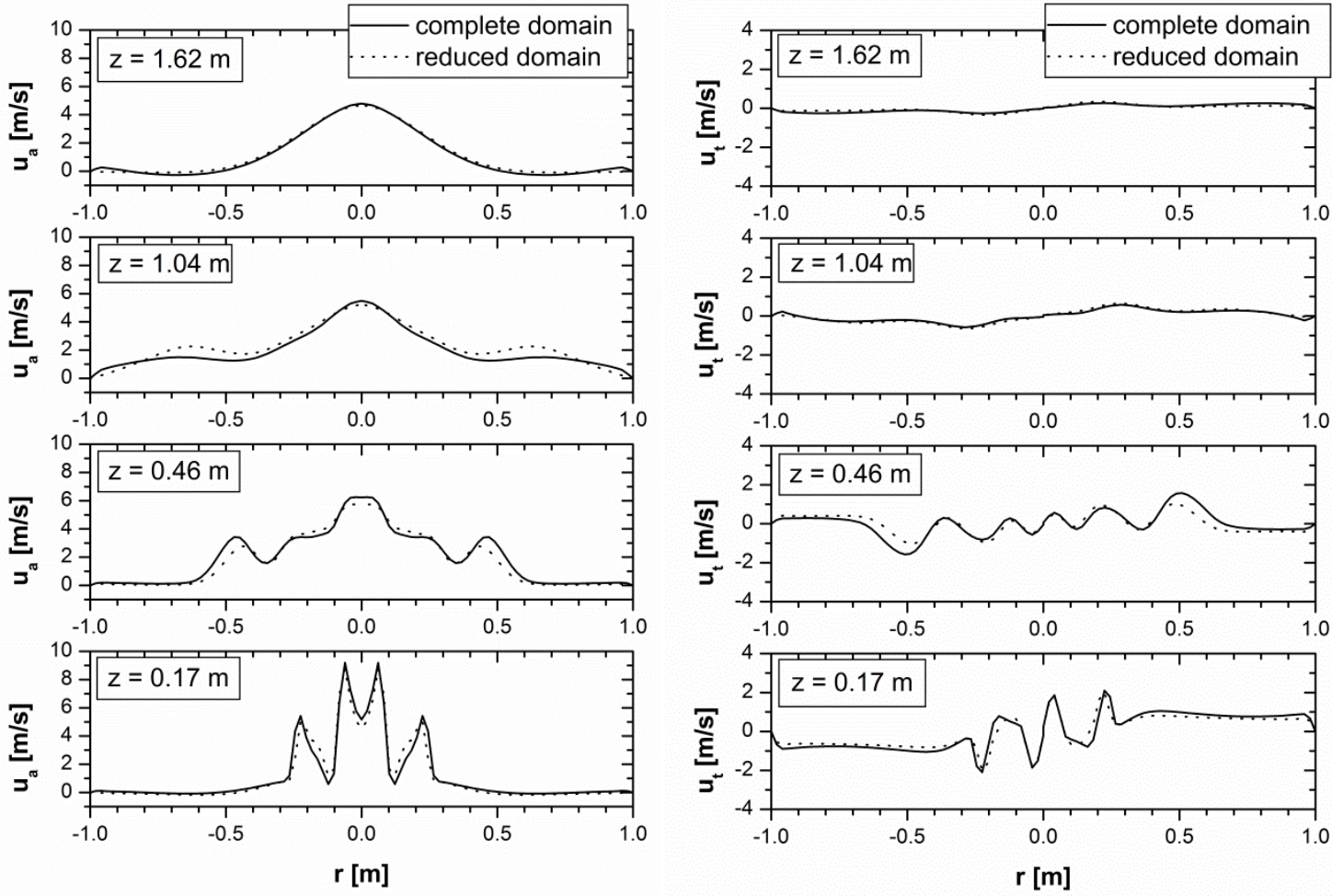

(a)

(b) 


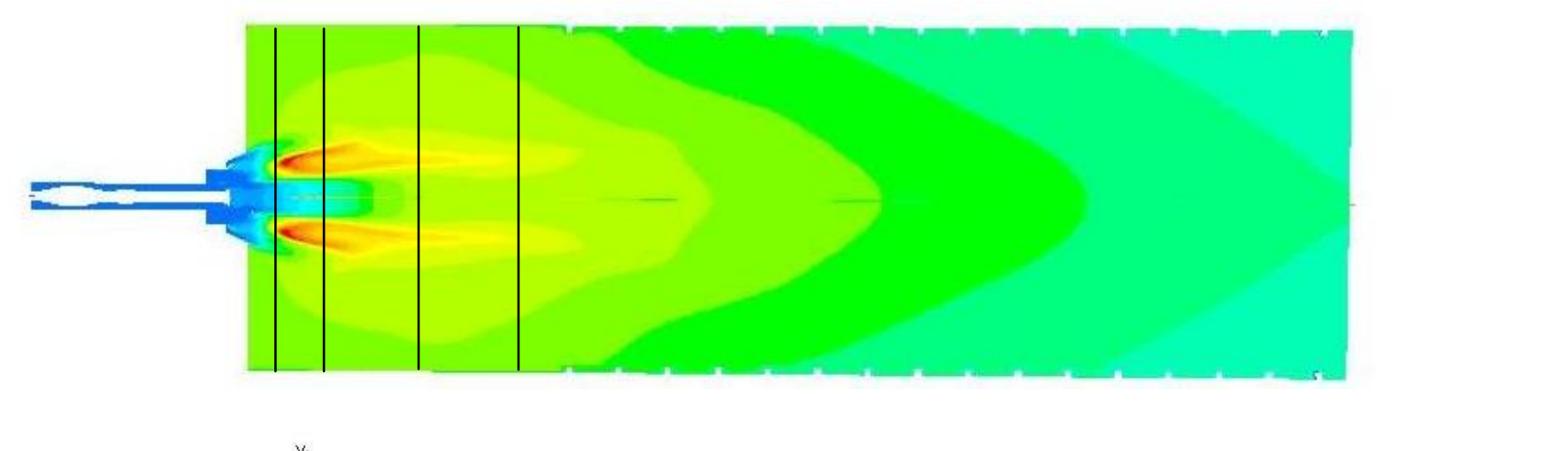

(a)
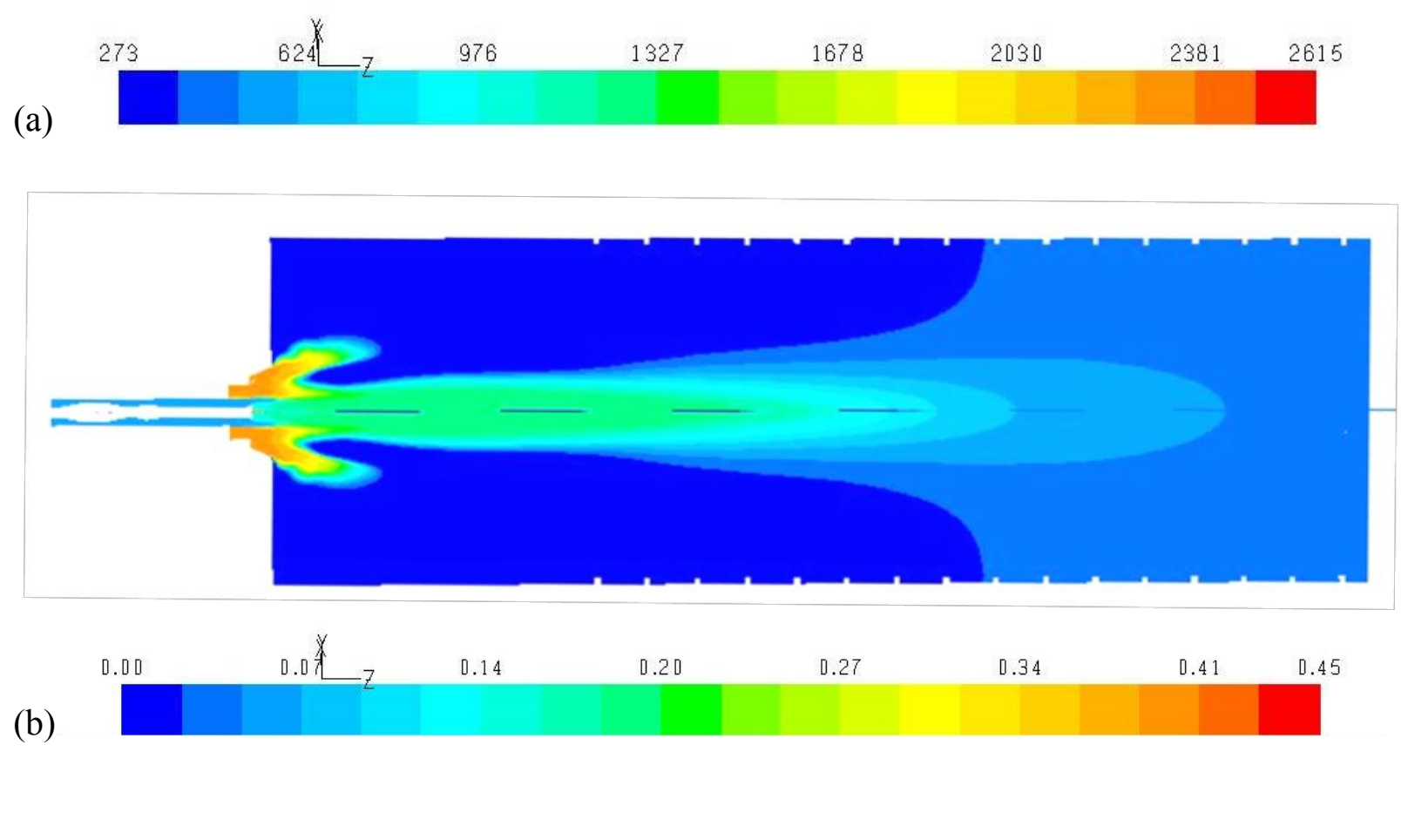

(b)

Figure 8

Figure 8

5

.

$$
\text { . }
$$
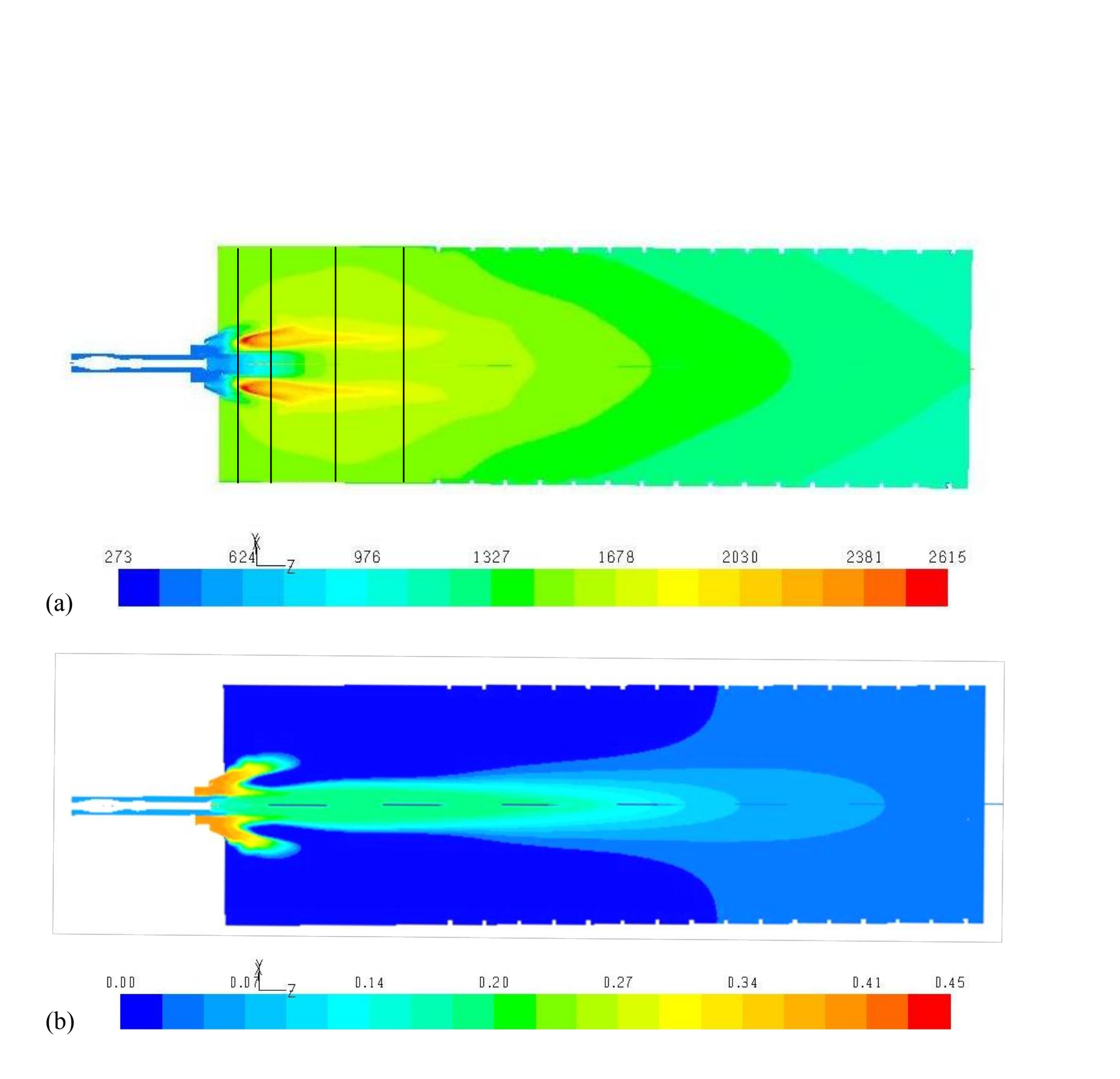

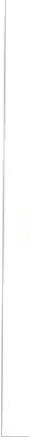


Figure 9

(a)

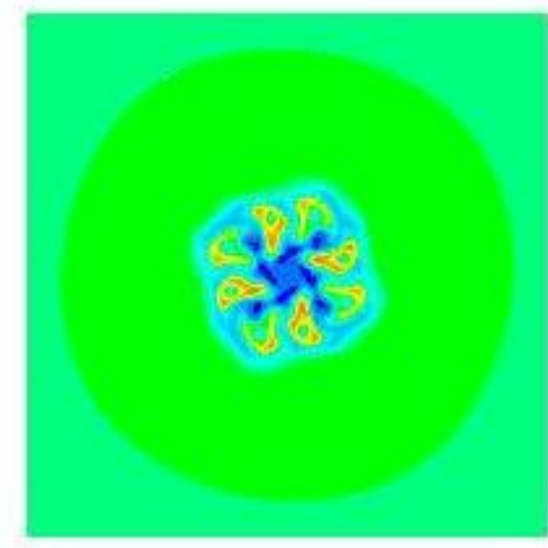

(b)

(c)

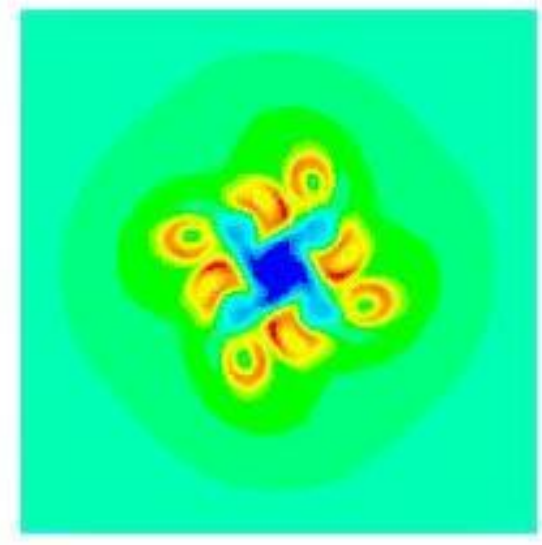

(d)
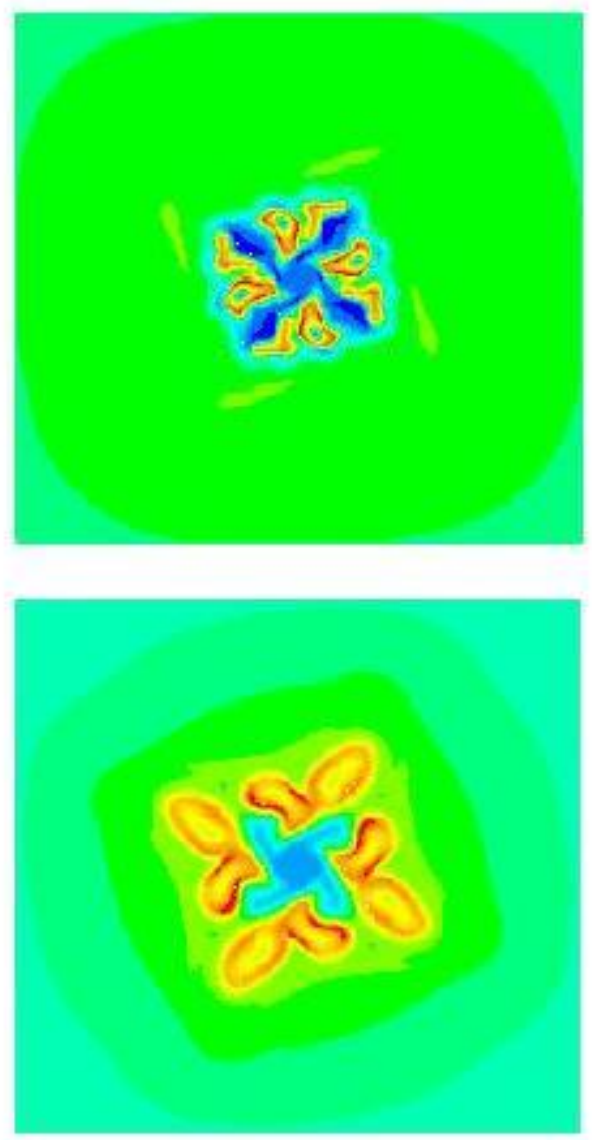
(a)
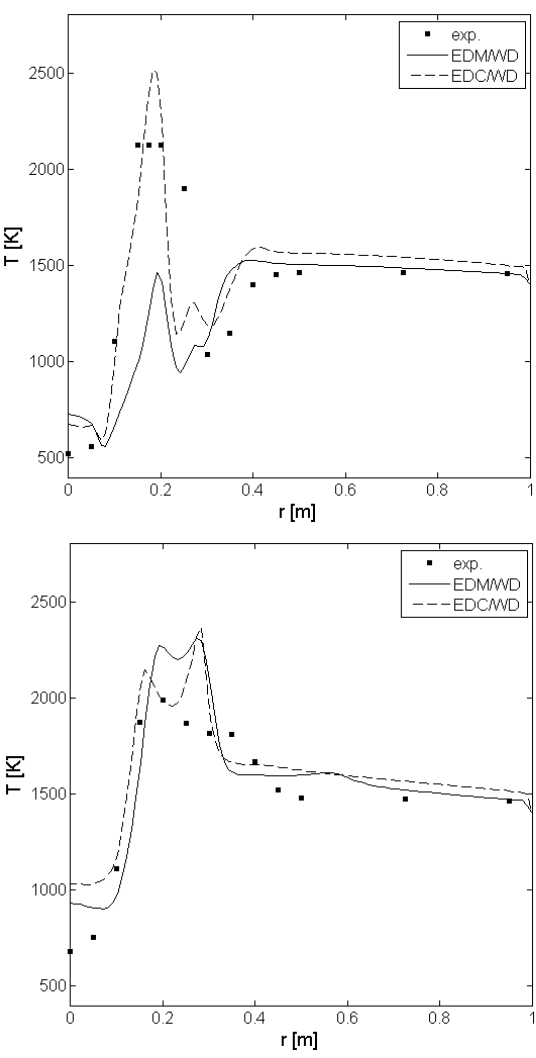

(b)

(c)
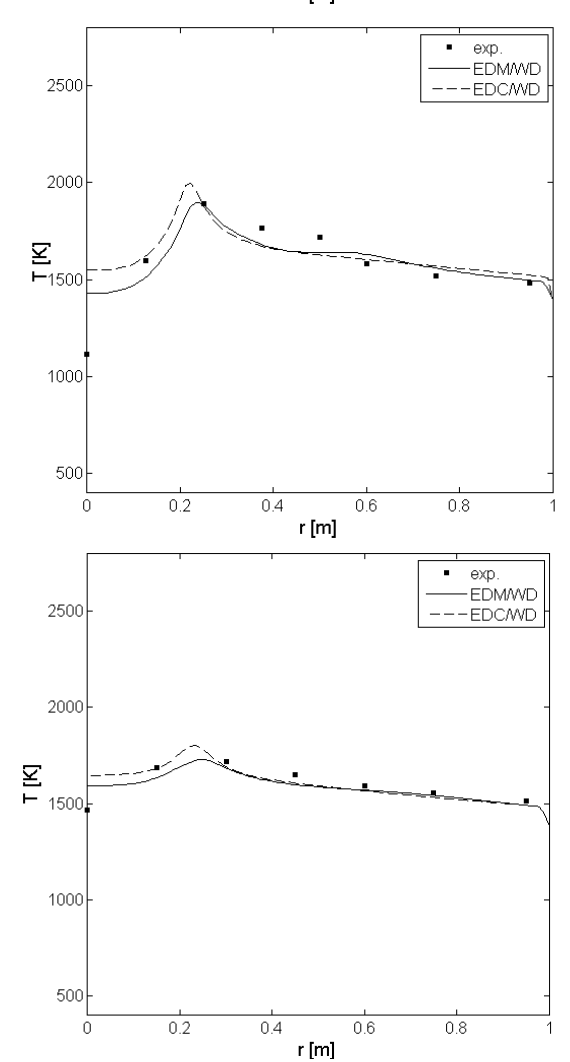

(d)
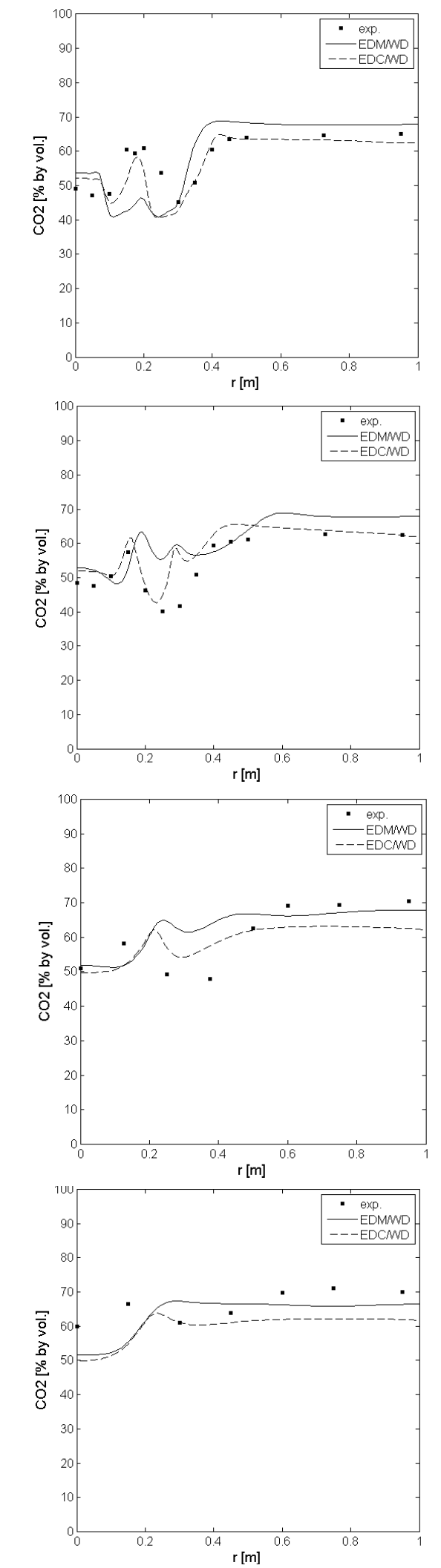
(a)
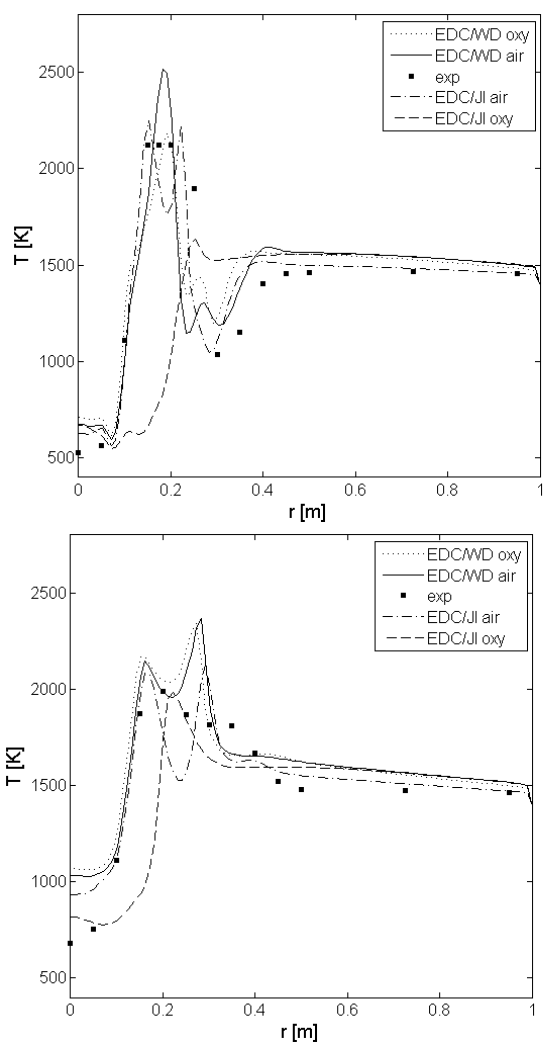

(b)

(c)
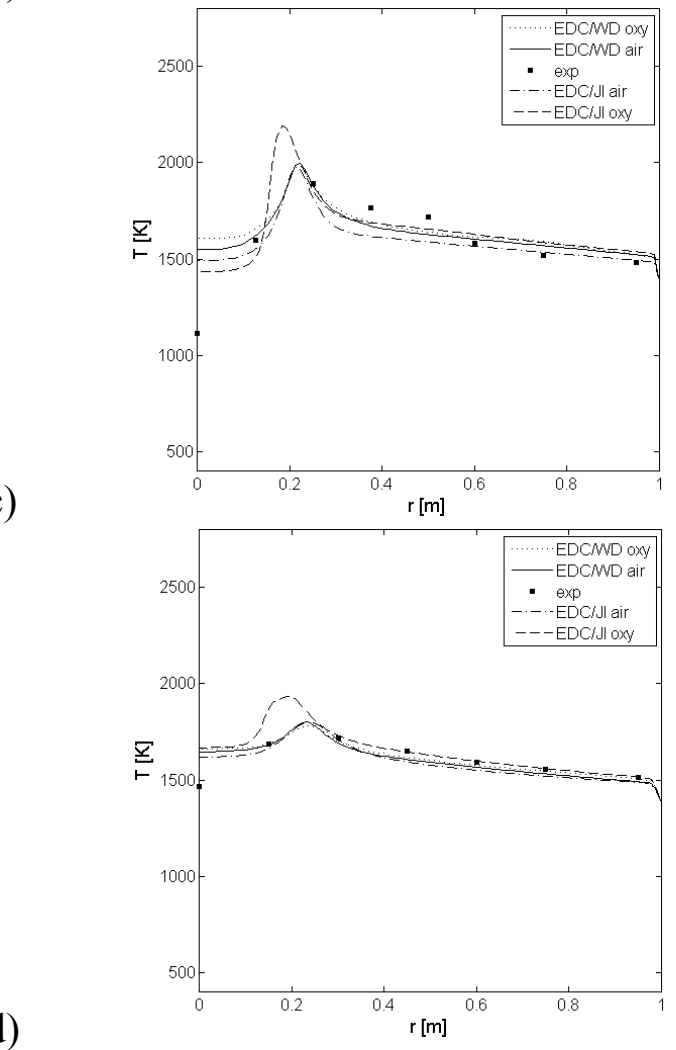

(d)
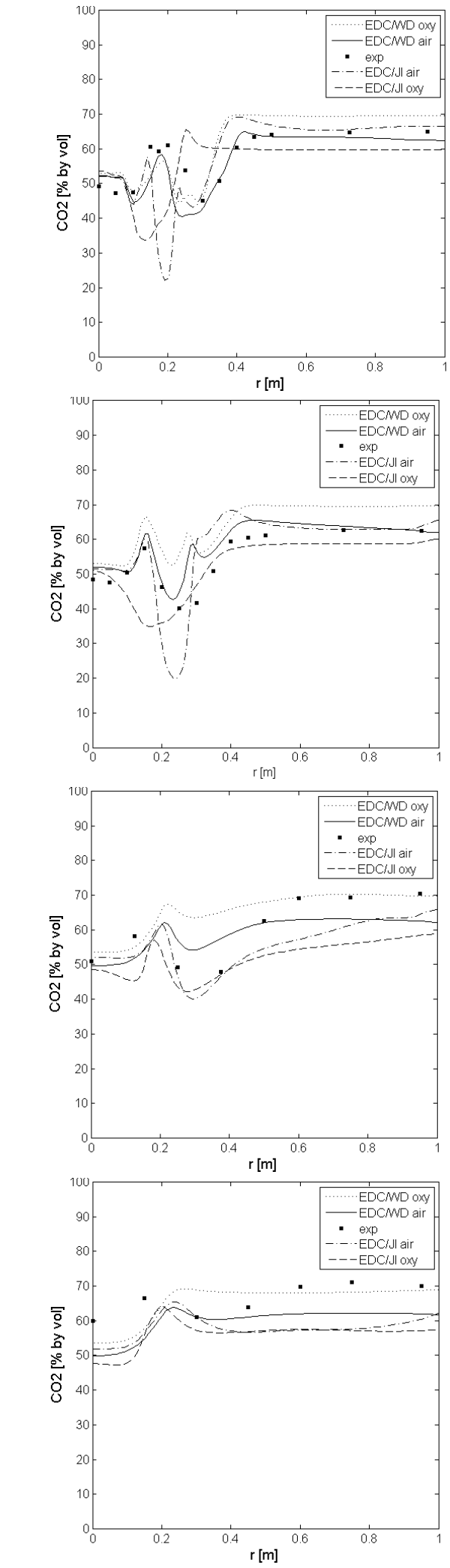
Figure 12

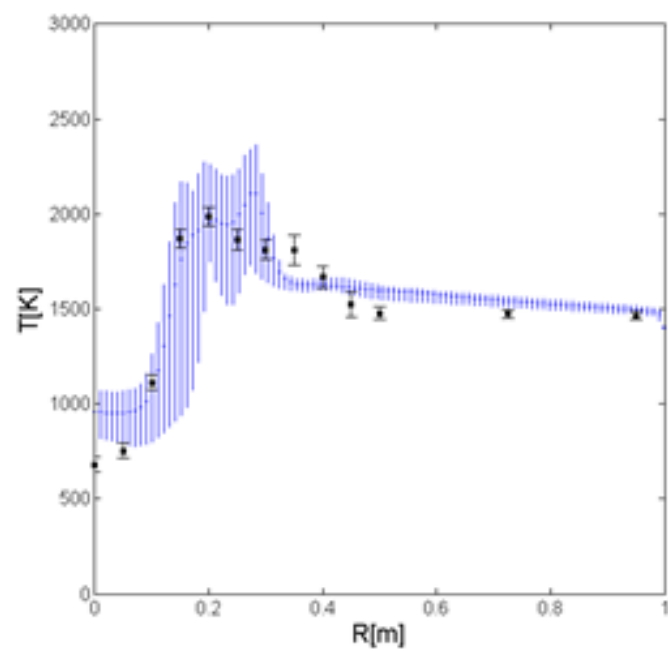

(a)

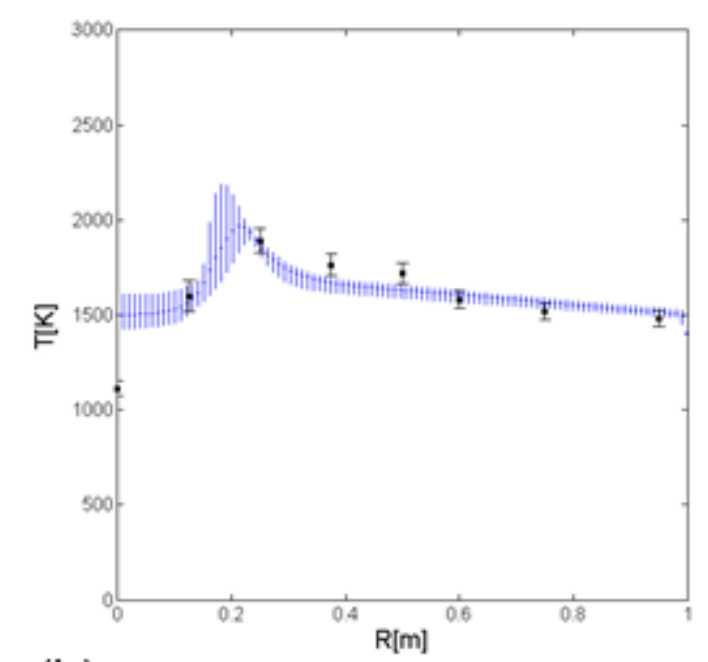

(b)$$
\text { ) }
$$

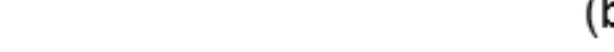



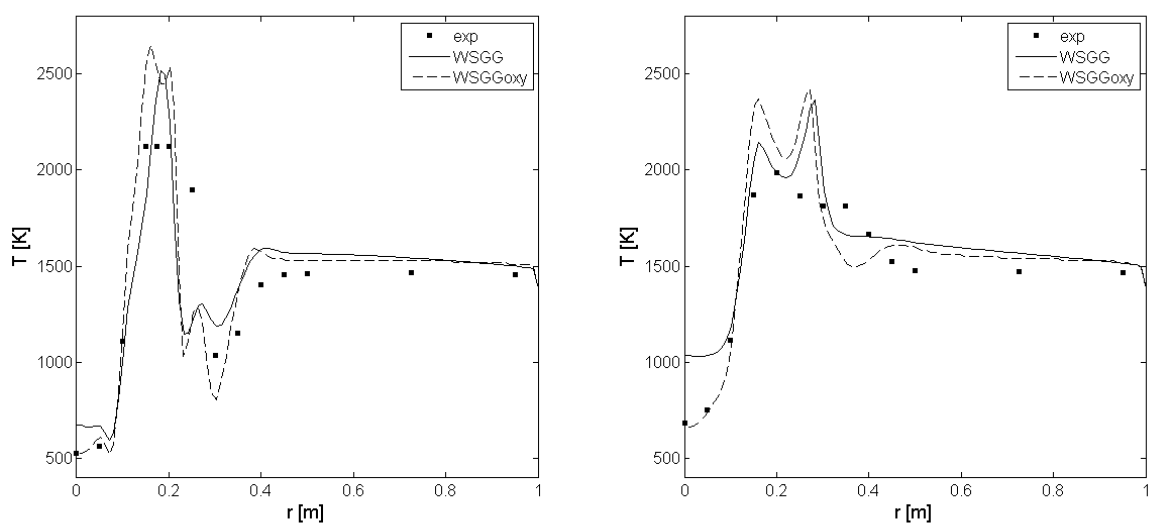

(a)

(b)
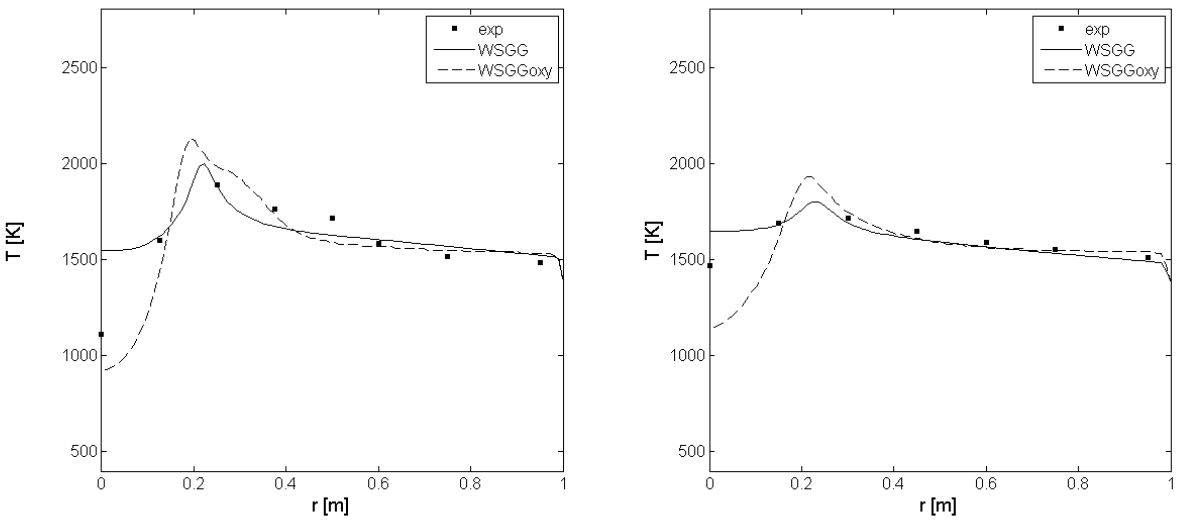

(c)

(d) 